Article

\title{
Ecological Efficiency Based Ranking of Cities: A Combined DEA Cross-Efficiency and Shannon's Entropy Method
}

\author{
Corrado lo Storto \\ Department of Industrial Engineering, University of Naples Federico II, Piazzale V. Tecchio 80, \\ Naples 80125, Italy; corrado.lostorto@unina.it; Tel.: +39-081-768-2932; Fax: +39-081-768-2154 \\ Academic Editor: Tan Yigitcanlar \\ Received: 9 October 2015; Accepted: 25 January 2016; Published: 29 January 2016
}

\begin{abstract}
In this paper, a method is proposed to calculate a comprehensive index that calculates the ecological efficiency of a city by combining together the measurements provided by some Data Envelopment Analysis (DEA) cross-efficiency models using the Shannon's entropy index. The DEA models include non-discretionary uncontrollable inputs, desirable and undesirable outputs. The method is implemented to compute the ecological efficiency of a sample of 116 Italian provincial capital cities in 2011 as a case study. Results emerging from the case study show that the proposed index has a good discrimination power and performs better than the ranking provided by the Sole24Ore, which is generally used in Italy to conduct benchmarking studies. While the sustainability index proposed by the Sole24Ore utilizes a set of subjective weights to aggregate individual indicators, the adoption of the DEA based method limits the subjectivity to the selection of the models. The ecological efficiency measurements generated by the implementation of the method for the Italian cities indicate that they perform very differently, and generally largest cities in terms of population size achieve a higher efficiency score.
\end{abstract}

Keywords: cross-efficiency; data envelopment analysis; Shannon's entropy; ecological efficiency; cities; ranking; Italy

\section{Background}

In the last decade, cities have gained a greater centrality in the economic and social growth of nations. The recent report delivered by the Brookings Institution indicates that in 2014 the economies of the 300 largest metropolitan areas accounted for $47 \%$ of global gross domestic product (GDP) and $38 \%$ of GDP growth [1]. According to recent estimates provided by Seto et al. [2], more than $80 \%$ of the national gross domestic product (GDP) is generated in urban areas. A recent worldwide research conducted by the McKinsey Global Institute on a sample of 600 cities estimates that between 2010 and 2050, the GDP of these cities is expected to double, while 23 megacities-cities having more than 10 million inhabitants—in 2007 generated 14\% of global GDP [3].

People move to and live in cities to have access to better jobs, education, health care, goods and services. More than half of the human population over the world is living in cities and towns, and, in the next decades, the number of people expected to live in cities will grow to $75 \%$, while population growth over the next 25 years will be concentrated in cities and towns $[4,5]$. The most urbanized areas are located in the American and Europe continents, respectively having about $80 \%$ and $70 \%$ of all inhabitants residing in cities and towns. However, while cities are the primary source of economic development and social prosperity, and house more than half of the world population, they are large users of resources, responsible for about $2 / 3$ of energy demand and greenhouse gas emissions [5]. The recent rapid and intense urbanization has often resulted in an over consumption of water, energy, raw 
materials, land, and production of waste and air pollution. Poor environmental quality and ecological efficiency, together with a scarce infrastructure development and traffic congestion, negatively affect the economic competitiveness, livability, and attractiveness of cities [6,7].

An important issue related to the implementation of an effective urban development strategy aimed at improving the ecological efficiency of a city is the adoption of a measurement framework, a set of performance indicators and, eventually, a synthetic index to rank and benchmark cities. The measurements provided by such indicators and the comprehensive index may be a useful tool to evaluate the success of the policies adopted by local governments to make cities more ecologically efficient, and, if necessary, to revise urban development plans and projects.

\section{Objectives}

Measuring and comparing the ecological efficiency of cities have become important elements to assess their livability and the performance of policies adopted by local governments to improve city environmental sustainability and attractiveness [8]. Cities that are more ecologically-efficient are able to reduce the over consumption of resources by minimizing the use of energy, materials, water and land, enhancing recyclability and lower the impact on environment by minimizing air pollution, not treated black and grey water discharges, waste disposal, as well as supporting the adoption of facilities for the production of energy from renewable sources [9].

Several measurement guidelines, frameworks, set of indicators and indices have been proposed by public organizations, consulting bodies and academic scholars. However, these have a number of shortcomings that make them not very useful for ranking cities. Particularly, many shortcomings are due to the model implemented to measure the ecological efficiency indicators and the way different indicators are aggregated to generate a unique measurement. Composite indices are increasingly used for performance monitoring, conducting benchmarking studies, and communicating the outcome of public policies. The main advantage associated with the utilization of a composite aggregate index is related to its intrinsic capability to provide a comprehensive and effective view of a certain phenomenon and to generate a ranking and compare different units under evaluation [10]. Generally, equal weightings are used to aggregate the different dimensions or indicators to generate an aggregate index. However, when multiple weightings are adopted, there are no sound justifications for the choice of different weights. Furthermore, often aggregate indexes available in literature do not provide an acceptable discrimination between units.

This paper proposes a comprehensive index based on the calculation of Data Envelopment Analysis (DEA) cross-efficiencies and Shannon's entropy index to rank cities with respect to their ecological efficiency score. This index has a number of advantages when it is compared to indexes proposed in the academic and industry literature. Particularly, it uses an endogenous weighting scheme to aggregate partial indicators that is generated from data themselves, avoiding the adoption of any subjective expert judgment. In addition, this index can be easily customized to the specific characteristics and needs of the context and to the availability of data to generate a more effective measurement of the city ecological efficiency by including different sets of indicators. Finally, it has a good discrimination capability. The index is used to compare and rank 116 provincial capital cities in Italy. While sustainability is a complex and multifaceted concept, this paper privileges the ecological dimension of it and a strict conceptualization of ecological efficiency circumscribed to environmental issues is adopted. As there is no agreement among scholars about the model that should be implemented to evaluate resource and environment efficiency, the methodological setting adopted to calculate the ecological efficiency of cities uses several DEA models to simultaneously measure environment and resource efficiency. Moreover, because each model calculates the city ecological efficiency as a cross-efficiency score from different perspectives, results from different DEA models are combined together by means of the Shannon's entropy index.

The rest of the paper is organized as follows. Section 2 reports an in-depth literature survey that focuses on the measurement of ecological efficiency both from a practice and an academic orientation; 
Section 3 illustrates the method to compute the ecological efficiency of cities, while Section 4 shows and discusses some major results emerging from the application of the method to a case study relative to a sample of Italian cities. Finally, Section 5 presents some concluding remarks.

\section{Measuring Ecological Efficiency: A Literature Survey}

Quantifying sustainability development has been a major concern of policy makers and academic scholars, and ecological efficiency indicators have been widely adopted to measure the sustainability of cities. The following sections illustrate some major contributions on the measurement of ecological efficiency both from practice-oriented and academy-oriented perspectives.

\subsection{The Practice-Oriented Contribution}

A variety of recommendations and guidelines have been proposed relative to the design, meaning and quantification of ecological efficiency indicators [11]. Several international organizations and NGOs have proposed measurement frameworks and indicators to assess environmental sustainability of urban areas or regions, by adopting some theoretical multidimensional models aimed at conducting benchmarking studies at a local level [12], at the country level [13], at the international level [14,15], and in the developing countries of the world [16]. The adoption of a set of standardized sustainability indicators is important to perform effective benchmarking. Indeed, as Olsthoorn et al. [17] claim, environmental indicators are usually constructed and applied by organizations on the basis of their specific standpoints. Furthermore, these indicators are often arbitrary and reflect only some dimensions of environmental sustainability and performance.

In 2011 the United Nations Economic and Social Commission for Asia and the Pacific (UN-ESCAP), the United Nations Economic Commission for Latin America and the Caribbean (UN-ECLAC), and the United Nations Human Settlements Program (UN-Habitat), in partnership with the Urban Design Lab of the Earth Institute of the Columbia University have jointly released the "Guidelines for developing eco-efficient and socially inclusive infrastructure", which provide practical tools for city planners and decision makers to reform urban planning and infrastructure design in developing countries, particularly in Asia and Latin America, according to the principles of ecological efficiency and social inclusion [18].

The Global Reporting Initiative has carried on a research project supported by the World Resource Institute, the United Nations Environment Programme (UNEP), several environment and social associations, the World Business Council for Sustainable Development (WBCSD) and certification agencies to define the "Sustainability Reporting Guidelines" as a common standard [19]. The Yale University has developed the global Environmental Performance Index (EPI) that is adopted to conduct benchmarking studies at both the national and provincial levels [20,21]. In the UK, the Sustainable Development Unit of Government and the Central Local Information Partnership Task Force on Sustainable Development (CLIP), together with a number of local governments have designed a set of indicators covering three dimensions of sustainability: environment, society and economy.

Since 1992, after the adoption of the Maastricht Treaty, the European Commission has showed concerns towards environmental sustainability. After the European Council held in Gothenburg in July 2001, sustainability development has become a major goal of the EU policies and a concern of EU countries. Since then, sustainable development indicators have become useful tools to measure and evaluate progress towards sustainable development in Europe. In 2008 the European Commission adopted a specific strategy for Climate Action. According to this strategy, the Member States will reduce their greenhouse gas emissions by at least $20 \%$ and boost the generation of energy from renewable sources to $20 \%$ of total consumption by 2020. Furthermore, the European Commission set the goal to reduce its primary energy consumption by $20 \%$ by 2020 . This strategy stressed the need for EU countries to increase energy efficiency. In 2013, the European Commission published the results of a survey conducted in 2012 that focused on the perception of the quality of life in 79 European cities and major suburban areas. The survey evaluated quality of life as a variable dependent on the perceived 
quality of relevant public services (health, transport, education, cultural and recreational activities, road cleaning, parks and public land, road maintenance); the perceived quality about some issues related to collective life in the cities (e.g., sport facilities, shops, job offer, housing, environment pollution); and the perceived quality about some personal issues of participants to the survey (e.g., overall satisfaction about life, job, etc.). This survey was fundamentally qualitative in nature. The statistical office of the European Union-EUROSTAT_-since 2004 provides statistics on some themes relevant to Europe, and, particularly, on transport, environment and energy, sustainable development, and quality of life. Data and indicators are freely available for research purposes [22].

There are a number of empirical studies aimed at identifying and measuring sustainability indicators and, finally, developing aggregated indices that are performed by private organizations.

The Economist Intelligence Unit (EIU), the research and analysis division of The Economist Group, sponsored by Siemens, conducts a yearly research project that covers more than 120 cities worldwide to calculate the Green City Index in order to provide city stakeholders with insights on better environmental policies and best practices [23]. Since 2009, the Green City Index (GCI) evaluates cities' sustainability on about 30 indicators. In particular, the $\mathrm{GCI}$ uses data relative to $\mathrm{CO}_{2}$ emissions, energy consumption, buildings characteristics, utilization of land, transport infrastructure, water and sanitization, waste collection and treatment, and air quality. The method that calculates the CGI uses both qualitative assessments of the city environmental policies and quantitative measurements available in official public databases. The calculation of the index is very flexible as it takes into account data availability. Therefore, the structure of the index changes from country to country.

The Dual Citizen LLC—a USA based consulting company_publishes the Global Green Economy Index ${ }^{\mathrm{TM}}$ (GGEI) that provides a measurement of the sustainability performance of 60 countries and 70 cities. Since 2010, this performance index is constructed by aggregating 32 indicators, classified over four main dimensions (leadership and climate change, efficiency sectors, market and investment, environment and natural capital) [24].

The global consulting company Mercer HR has developed a methodology to rank cities with respect to the level of quality of life. The ranking index utilizes 39 indicators grouped in the following categories: political and social context, economical context, cultural context, health, education, public services and transport, leisure, consumption goods, public housing, environment [25]. The weekly newspaper "The Economist" employs data collected by the Mercer HR survey to develop a different index to rank cities in a smaller sample.

Every year, the European consultancy firm Arcadis calculates the Sustainable Cities Index for a sample including the more important 50 cities in the world. Cities are classified according to three sub-indices-People, Planet and Profit. These indices are constructed using indicators that measure environmental quality, such as energy consumption, greenhouse gas emissions, amount of energy generated from renewable sources, and waste recycling rate. [26,27].

The international technical literature also includes the following indices, which for the sake of brevity are only listed here: Climate Change Performance Index [28], Environmental Performance Index [29], Global Cleantech Innovation Index [30], Green Economy Report [31], Low Carbon Economy Index [32], Renewable Energy Country Attractiveness Index [33].

In Italy, in 2010, the National Council for Economics and Labour (CNEL) and the National Statistical Institute of Italy (ISTAT) jointly launched the BES project—Benessere Equo e Solidale—aimed at evaluating citizen wellbeing in Italian major cities [34]. The project utilizes a hierarchical frame of indicators grouped in 12 relevant higher-level indices. The second order indicators include measurements relative to the integrated water service, air quality, parks and urban green, road cleaning, urban waste collection and treatment. However, the BES project does not provide a synthetic final index to rank cities. Some indicators are available only at the regional level, while some indicators are available at the city level too.

Since 25 and 20 years, respectively, the two most important Italian economic newspapers-the Sole24Ore and ItaliaOggi- every year carry on separate surveys that deliver two rankings of the Italian 
provincial capital cities with respect to the quality of life. Particularly, the Sole24Ore study utilizes a set of 36 indicators articulated into six thematic areas (standard of living, business and jobs, environment and public services, crimes, population, leisure). While the thematic areas remain unchanged, the individual indicators of each area can be modified or substituted by new indicators to provide a more articulated evaluation of the city quality of life [35]. However, changing the set of indicators and the weighting scheme from year to year can make the rankings and comparison of cities meaningless. The survey performed by ItaliaOggi evaluates the quality of life in the Italian provinces adopting a set of 77 indicators clustered into eight main areas, which are weighted differently. The project compares only provincial areas and provides more in depth information for a limited number of large cities [36].

The project Ecosistema Urbano promoted by Legambiente, a nonprofit green association, has a greater focus on environmental issues and the multidimensional sustainability indicators are used as a reference to develop the "environment" thematic area of both surveys carried on by Sole24Ore and ItaliaOggi [37]. The project Ecosistema Urbano has now developed a well-accepted set of 20 environment indicators that assess quality, pressure and management of environmental resources and are measured year by year for all Italian provincial capital cities. These indicators are aggregated to generate a single index and obtain a unique ranking. Every year, cities showing better environmental performance are awarded a prize.

Finally, several local governments in Italy carry on customer satisfaction survey based on the usage of a set of indicators that often have been purposefully designed. However, many times the set of indicators is not based on the use of variables and measurements that have been previously scientifically validated. Indeed, as local governments try to promote cities as livable, green and environmentally sustainable, indicators are chosen ad hoc to evaluate only some aspects and measure the achievement of improvement goals that are easily achievable.

\subsection{The Academy-Oriented Contribution}

Several scholars have suggested methodological frameworks and indicators to measure the ecological efficiency of urban and regional areas. Mori and Christodoulou [38] reviewed major sustainability indices-Ecological Footprint (EF), Environmental Sustainability Index (ESI), Dashboard of Sustainability (DS), Welfare Index, Genuine Progress Indicator (GPI), Index of Sustainable Economic Welfare, City Development Index, emergy/exergy, Human Development Index (HDI), Environmental Vulnerability Index (EVI), Environmental Policy Index (EPI), Living Planet Index (LPI), Environmentally-adjusted Domestic Product (EDP), Genuine Saving (GS)—and finally discussed conceptual requirements necessary for building an index useful to measure city sustainability. In particular, they claim that the availability or the ad hoc creation of a set of indices and/or indicators is an important part of the evaluation of city sustainability.

Literature also suggests sets of indicators and aggregated indices that encompass specific dimensions of urban sustainability, such as energy use [39,40], and water consumption [41]. However, even though the importance of indicators and indices is well acknowledged, there is no agreement about the choice of the indicators and the construction of aggregate indices. Nan and Williams [42] conducted an in-depth historical review on the literature relative to the eco-city and related-concepts, and the performance indicators commonly used for evaluating the sustainability of urban areas. The scholars found that there are several definitions of eco-cities that privilege different dimensions of sustainability and eco-efficiency and even though there has been an effort to integrate these concepts there is no consensus about what dimensions are more or less important. The authors assert ([42], p. ii) "[... ] there is some high-level consensus on the types of phenomena that should be measured in evaluating sustainable, green, eco-, and similarly labeled cities. All indicator systems measure performance related to energy and climate change. Fewer, but still a majority, measure air quality and land use impacts. Even fewer, but still a majority, measure water quality and social health impacts. Waste, transportation, and economic impacts are least commonly measured, but nevertheless are measured by a majority of indicator systems. Despite some consensus on the most important general categories to be measured, there is little consensus about the priority issues to be 
evaluated in each category. There is also little agreement on the methodology by which indicators for each of these areas should be chosen other than relying on data that are already available and on expert opinion regarding what indicators can best be used to measure progress. Threshold benchmarks are not commonly used, and there is little agreement on how indicators or indicator categories should be weighed against each other in forming an aggregated score that could be assigned to a city if a single summary indicator is desired."

In general, scholars implement different methods and approaches to generate measurements to evaluate sustainability and ecological efficiency of cities, i.e., ecological footprint analysis (EFA) [43,44], emergy accounting [45], urban metabolism analysis [46], ratio-approach [47], parametric and non-parametric methods (e.g., stochastic frontier analysis and DEA) [48-50], and Analytical Hierarchy Process (AHP) [51].

Implementing these methods and approaches has both advantages and disadvantages. Li et al. [52] proposed a method based on the calculation of the ecological footprint as an aggregate environmental indicator for evaluating the eco-efficiency of residential development at city level. The method was implemented to compare three Chinese cities. However, the scholars regret that data collection and analysis was very complex and time consuming. Geng et al. [53] used ecological footprint analysis for evaluating urban sustainability and comparing two industrial cities in China and Japan. As they claim, even though the ecological footprint analysis is a useful method for evaluating city sustainability, it has some shortcomings. The difficulty to get accurate information about products' life cycles in the case of long and complex production chains, problems related to double-counting, and a lack of an in depth knowledge about the production processes make the implementation of the method not easy and not effective.

A number of researchers use the "emergy" approach to obtain a comprehensive way to value an ecological system that produces goods and delivers services in terms of the amount of energy, which is used directly and indirectly and is conveniently expressed in solar emjoules as a measuring unit [54]. For instance, Pizzigallo et al. [55] used an emergy based analysis to evaluate the environmental sustainability of the Province of Modena in Italy. However, this approach has raised some criticism for its being idiosyncratic, computationally complex and data intensive [56]. Scholars have also adopted the metaphors of the living organism and the metabolic process to describe the urban ecosystem and the economic and social activities that people, businesses and infrastructure assets perform when resources are consumed and goods and/or services are produced [57,58]. The Urban Metabolism Analysis has been utilized as an accounting tool to measure the balance between the material flows in cities and, finally, develop eco-efficiency indices [46]. The implementation of this latter approach that is based on the analysis of material flows employs more practical measuring units that the non-academic stakeholders can more easily understand. However, the approach has been criticized [59]. Indeed, the suitability of the Urban Metabolism (UM) framework in applying the concept of the city as a biophysical system has been questioned, emphasizing " [... ] a weakness of UM as the tendency to conflate organism and ecosystem, often using the terms interchangeably" ([59], p. 757).

Yin et al. [60] used measurements of ecological efficiency indicators for evaluating the progress towards sustainability of provincial capital cities in China. Wang et al. [61] conducted case study analysis to evaluate the progress of ecological construction in the Shandong province in China by means of a pre-set of qualitative and quantitative indicators. Sustainability and ecological efficiency indicators have often been developed as ratios, such as water consumption to inhabitants, and amount of $\mathrm{CO}_{2}$ produced per year.

A large amount of academic research is focused on the effort to implement weighting factor methods and techniques in the field of environment and sustainability in order to aggregate several indicators to obtain a single comprehensive index [62-65]. In general, four approaches have been followed to weight individual indicators: (a) using arbitrary (subjective) weights, i.e., the same weights for all indicators; (b) generating weights from social preferences relative to different indicators that are associated to specific sustainability dimensions; (c) using expert judgment to build a set of weights; (d) generating weights endogenously from the dataset itself (for instance, by implementing 
non-parametric linear programming techniques or statistical analysis aimed at reducing the amount of variables), thus avoiding the introduction of any subjectivity linked to personal preferences.

When an arbitrary set of weights is utilized to aggregate individual indicators, the choice of one or more weights may not always be easily justified by a sound scientific argumentation because cities are very complex systems in which the interaction among sustainability policies, human behavior, infrastructure assets performance, resource use, etc. can be difficult to understand [66]. One common method that partially avoids arbitrariness in the selection of weights is the AHP method. Michael et al. [67] adopted AHP to rank and prioritize a set of urban sustainability indicators for Malaysia. Aldegheishem [68] evaluated the urban sustainable development for Riyadh city by implementing AHP. Specifically, 13 second-level sustainability indicators were grouped into three first-level indicators after generating weights by means of an analytical hierarchy process. By means of AHP, Hesari et al. [69] investigated the priorities of sustainable development components in improving the old fabrics of Isfahan city. However, weights generated by implementing AHP can be to a great extent subjective because they are provided by expert judgment. Moreover, when the number of indicators used is great, the involvement of experts and the process that generates weights can be time-consuming. Furthermore, even using AHP has the same drawbacks of all methods that choose subjective weights. One major problem is the replicability of the weighting set as it is very unlikely that different experts working independently would assign the same weights to all indicators [66].

Implementing statistical (parametric) methods and techniques allows obtaining objective weights, and, in some cases, determining to what extent an indicator's weight is approximately proportionate to the sustainability performance outcome. These methods include generally multivariate regression analysis, principal component analysis (PCA), and stochastic frontier analysis (SFA) [65]. Using data for OECD and non-OECD countries over a period of 20 years, Sengupta et al. [70] showed that the aggregation of sustainability indicators to form a unique index coupled with the implementation of multivariate statistical analysis provides important insights. Scholars showed that over the 20-year window some indicators have shifted in their importance in influencing the overall environmental index, while others have remained relatively irrelevant. Cuesta et al. [48] implemented a parametric stochastic method to calculate the distance from the environmental efficiency frontier. Even though these methods have the potential to provide robust results, limitations due to sample size and data availability make it impossible to estimate weights from data. DEA has become very popular as a non-parametric technique to measure environmental performance [71]. DEA has the advantage over other classification and ranking methods commonly used of its great flexibility in the generation of weights, ranging from a full objectivity to a large subjectivity. Indeed, weights can be generated either endogenously from data themselves, or taking into account the decision-maker judgment using various forms of restriction constraints added to the analysis. Zhou et al. [72] conducted an in-depth literature survey on the application of DEA to environment and energy studies. Zhou et al. [73] discussed the environmental DEA technologies that exhibit either non-increasing returns to scale or variable returns to scale. Zhou et al. [74] developed a non-radial DEA model and a non-radial Malmquist environmental efficiency to measure change of environmental performance of 26 OECD countries from 1995 to 1997. Two important advantages of DEA over parametric multivariate statistical methods are that it more easily accommodates both multiple inputs and multiple outputs, and it does not require any specific functional form to be imposed on the ecological efficiency model. Since its introduction, a large number of extensions to basic DEA models have appeared to deal with environmental-related benchmarking analyses. DEA has been especially implemented to evaluate cities' ecological efficiency. Cherchye and Kuosmanen [75] analyzed several DEA applications concerning country sustainability development. Lu and Lo [76] implemented DEA to rank 31 Chinese regions with respect to their sustainability. Wang et al. [47] adopted a meta-frontier function and a non-radial directional distance function to construct an index that at the same time calculates the performance achieved by coupling energy savings and emissions reductions. The method was used to evaluate energy-efficiency performance of 209 Chinese cities. Wang et al. [77] constructed three 
levels of regional eco-efficiency indicators by analyzing the flow of materials and implemented DEA to measure the eco-efficiency degree of Tongling City between 1990 and 2008. Huang et al. [78] proposed an extended DEA model that combines global benchmark technology, undesirable output, super efficiency and slacks-based measure to investigate the dynamics of regional eco-efficiency in China from 2000 to 2010. Üstün [79] used DEA to evaluate environmental efficiency of Turkish cities. The scholar evaluated the environmental efficiencies of 81 Turkish provinces in 2010 using four DEA models. Further, by using these measurements, he developed environmental efficiency maps of Turkey. The scholar employed the following inputs: total water resources, total environmental budget (i.e., current expenditure and total environmental expenditure), and the following outputs: total amount of solid waste collected, number of people taken sewage service, number of people taken potable sewage service, the reciprocal of the maximum $\mathrm{PM}_{10}$ and $\mathrm{SO}_{2}$ concentrations. Yin et al. [60] applied DEA to perform an eco-efficiency study of 30 Chinese provincial capital cities using environmental pollution as an undesirable output, and a modified super-efficiency model for ranking. Yu and Wen [80] utilized standard Banker-Charnes-Cooper (BCC) and Charnes-Cooper-Rhodes (CCR) DEA models and the Malmquist index to evaluate the status quo and future trends of 46 typical cities in China.

\section{The Method}

As mentioned earlier, the main goal of this study is to develop a method to compute a comprehensive index to measure the ecological efficiency of cities useful to generate rankings and conduct benchmarking analyses. The method assumes that individual cities can be stylized as (ecological) production functions that generate different outputs (i.e., products and services) through the combination of a set of inputs. The household water consumption, the amount of households served by black water depuration plants, and the installed photovoltaic power are examples of outputs. Of course, in the perspective of the measurement of the city ecological efficiency, the outputs can be of different types, either good or bad. Thus, the household water consumption can be considered a bad output, while the number of photovoltaic power facilities installed on the roofs of public buildings and the number of households served by black water depuration are good outputs of the production function. The city administrators may adopt particular measures and policies to promote the diffusion of virtuous behaviors and best practices relative to sustainability among inhabitants, i.e., the limitation or even the restriction of vehicle use in downtown areas, the adoption of no drive-days programs, the control of truck movements, a set of incentives to differentiate waste and recycling as annual fee reduction, etc. In order to produce outputs, cities have to consume a certain amount of resources. In general, the bigger the city size, the larger the amount of resource consumption will be. In general, both the size of the city territory and population are good proxies of the amount of the resources consumed by the city production process. One city can be more ecologically efficient than another city which has about the same population and territory extension if it produces a larger amount of good outputs, i.e., the amount of differentiated and recycled waste, and a lower amount of bad outputs, i.e., household electricity and water consumption.

Every city is associated with a specific production function that utilizes the same typologies of inputs and outputs. The capability of the city to generate the largest amount of good outputs as products and services that have a minimum impact on the environment and the lowest production of bad outputs that, vice versa, have a negative impact on environment with the same amount of inputs (population and territory area) is denominated ecological efficiency. Therefore, every city achieves a different ecological efficiency measurement as it has a different capability to generate good outputs limiting the production of bad outputs. Given this definition of ecological efficiency, a relative measurement of it can be obtained by implementing a non-parametric frontier approach based on DEA. DEA is a robust, standardized and transparent benchmarking technique [81-83], and literature has emphasized the advantages of using it to conduct efficiency analyses, in particular [83,84]: (a) it is an effective technique for measuring the efficiency of units in the presence of multiple outputs and multiple inputs; (b) it does not need any specific assumption relative to the type of production 
function to combine inputs and outputs; (c) it avoids introducing any subjective judgment or estimate in the analysis.

The proposed method to obtain a comprehensive measurement of the ecological efficiency of a city is developed in two steps: (1) the calculation of efficiency scores by implementing several DEA models adopting different perspectives; (2) the calculation of cross-efficiency scores; and (3) the combination of the efficiency scores by computing the Shannon's entropy index.

\subsection{Step 1: the Calculation of the Individual Efficiency Scores}

Since its first introduction in 1978, DEA has been widely adopted as a powerful and effective methodology for modeling operational processes of certain units that convert multiple inputs into multiple outputs and measuring their efficiency in order to conduct benchmarking studies [81]. As a non-parametric linear programming technique, DEA measures the efficiency of each unit (denominated DMU, Decision Making Unit) in a sample as the ratio of weighted outputs over weighted inputs. In particular, the efficiency of a DMU is measured relatively to similar DMUs with the goal to estimate the frontier that is associated to the best practice for the sample under evaluation. As Cooper et al. [82] claim, DEA is a technique that is aimed at measuring distances from efficient frontiers rather than at identifying central tendencies as it happens in statistical regression.

Assume that there is a set of $n$ DMUs to be evaluated, and each DMU $j(j=1, \ldots, n)$ produces $s$ different outputs using $m$ different inputs which are denoted as $y_{r j}(r=1, \ldots, s)$ and $x_{i j}(I=1$, $\ldots, m)$ respectively.

For any evaluated DMU $k$, the relative efficiency score is generally defined as the ratio of the weighted sum of outputs over the weighted sum of inputs, that is

$$
E_{k k}=\frac{\sum_{r=1}^{s} u_{r k} y_{r k}}{\sum_{i=1}^{m} v_{i k} x_{i k}}
$$

$v_{k}=\left(v_{1 k}, \ldots, v_{m k}\right)$ and $u_{k}=\left(u_{1 k}, \ldots, u_{s k}\right)$ are the input and output weighting vectors for the evaluation of DMU $k$, while $u_{r k}$ and $v_{i k}$ are respectively the multipliers of the outputs and the inputs.

Assuming an input orientation and that there is no constant proportionality between inputs and outputs along the efficient frontier, a measurement for the relative efficiency of DMU $k$ can be obtained by solving the following multiplier model (the dual of the envelopment model) denoted as BCC DEA [85]:

$$
\begin{aligned}
\operatorname{Max} \frac{\sum_{r=1}^{s} u_{r k} y_{r k}+u_{* k}}{\sum_{i=1}^{m} v_{i k} x_{i k}} \\
\text { s.t. } \quad \frac{\sum_{r=1}^{s} u_{r k} y_{r j}+u_{* k}}{\sum_{i=1}^{m} v_{i k} x_{i j}} \leqslant 1 \quad j=1, \ldots, n \\
u_{r k}, v_{i k} \geqslant 0, u_{* k} \text { free, } \quad r=1, \ldots, s \quad \text { and } \quad i=1, \ldots, m
\end{aligned}
$$

In this model, the variable $u_{* k}$ is added to take into account different returns to scale along the efficient frontier. 
A measurement for the relative efficiency of DMU $k$ can be obtained by solving the following linear program, as follows [85]:

$$
\begin{gathered}
\operatorname{Max} \sum_{r=1}^{s} u_{r k} y_{r k}+u_{* k} \\
\text { s.t. } \sum_{i=1}^{m} v_{i k} x_{i k}=1 \\
\sum_{r=1}^{s} u_{r k} y_{r j}-\sum_{i=1}^{m} v_{i k} x_{i j}+u_{* k} \leqslant 0 \quad j=1, \ldots, n \\
u_{r k} \geqslant 0, v_{i k} \geqslant 0, u_{* k} \text { free, } \quad r=1, \ldots, s \quad \text { and } \quad i=1, \ldots, m
\end{gathered}
$$

Model Equation (3) is solved $n$ times, once for every DMU in the set. For each DMU $k$, a set of optimal input weights $v_{1 k}{ }^{*}, \ldots, v_{m k}{ }^{*}$, and output weights $u_{1 k}{ }^{*}, \ldots, u_{s k}{ }^{*}$ can be obtained by solving the above model Equation (3).

The ratio

$$
E_{k k}=\frac{\sum_{r=1}^{s} u_{r k}^{*} y_{r k}+u_{* k}}{\sum_{i=1}^{m} v_{i k}^{*} x_{i k}}
$$

is referred to as the BBC efficiency of DMU $k$ when $u_{k}{ }^{*}$ and $v_{k}{ }^{*}$ are the optimal solution to model Equation (3). This measurement of efficiency reflects the self-evaluation of DMU $k . E_{k k}=1$ if DMU $k$ is $100 \%$ efficient, and $E_{k k}<1$ if DMU $k$ is inefficient.

\subsection{Step 2: the Calculation of the Cross-Efficiency Scores}

The common DEA models are unable to generate useful rankings across DMUs because more than one of them might be scored as $100 \%$ efficient by the mathematical programming algorithm. Additionally, because every DMU has its own set of weights, all of its weight might be assigned to a single output and input, making the efficiency analysis unrealistic. A promising approach to alleviate the weak discrimination capability of the basic DEA models is based on the calculation of the DMU cross-efficiency score [86]. While in the traditional DEA models the measurement of a DMU efficiency is based only on self evaluation, by assigning the most favorable set of weights for outputs and inputs to maximize its efficiency (that is to say, from an optimistic perspective), in the DEA cross-efficiency approach a peer evaluation together with a pure self evaluation of DMUs are performed [87]. Ranking procedures based on the calculation of cross-efficiency scores have a number of advantages [88,89]. Particularly, they do not need the introduction of unrealistic weighting schemes provided by expert judgment, and generate a unique DMU ranking to differentiate between good and poor performers. A DMU which achieves a high cross-efficiency score has been evaluated passing a more rigorous test, because it has been considered efficient by the majority of its peers and not only by itself. The method to calculate DMUs cross-efficiencies can be formulated as follows [86,90].

The cross-efficiency of each DMU $j$ denominated as $E_{k j}$ can be calculated using the optimal values of DMU $k$ as follows:

$$
E_{k j}=\frac{\sum_{r=1}^{s} u_{r k}^{*} y_{r j}+u_{* k}}{\sum_{i=1}^{m} v_{i k}^{*} x_{i j}} j \neq k \text { and } j=1, \ldots, n .
$$

These values are used to obtain an $n \times n$ cross-efficiency matrix, in which the diagonal entries show the conventional DEA efficiency scores of the DMUs (self evaluation) and the off-diagonal cells give the cross-efficiency scores (peer evaluation). In order to get the final efficiency score and a ranking of the DMUs, cross-efficiencies must be aggregated. Table 1 shows details. The average of cross-efficiencies is used as an aggregation method (average method). 
When the DMU $k$ multipliers are used to calculate the efficiency of the other DMUs in the cross-efficiency formulation, if $u_{* k}$ is negative the expression $\sum_{r=1}^{s} u_{r k} y_{r j}+u_{* k}$ may be negative. Thus, in the input orientation approach the efficiency of DMU $j$ may be negative when computed using the multipliers of DMU $k$. To avoid negative cross-efficiencies, Soares de Mello et al. [91] suggest adding the additional constraint $\sum_{r=1}^{s} u_{r k} y_{r j}+u_{* k} \geqslant 0$ in model (3).

The weights obtained from model (3) are usually not unique depending on the optimal solution arising from the particular LP software in use. Consequently, the cross-efficiency scores computed according to model (5) remain arbitrarily determined. To avoid such arbitrariness, secondary goals that optimize the input and output weights have been suggested in the literature $[86,89,90]$.

Table 1. Cross-efficiency matrix for $n$ DMUs and the calculation of cross-efficiency scores.

\begin{tabular}{ccccc}
\hline DMU & \multicolumn{3}{c}{ Target DMU } & Average \\
\cline { 2 - 4 } & $\mathbf{1}$ & $\mathbf{2}$ & $\mathbf{n}$ & Cross-Efficiency \\
\hline 1 & $E_{11}$ & $E_{12}$ & $E_{1 n}$ & $\frac{1}{n} \sum_{j=1}^{n} E_{1 j}$ \\
\hline 2 & $E_{21}$ & $E_{22}$ & $E_{2 n}$ & $\frac{1}{n} \sum_{j=1}^{n} E_{2 j}$ \\
\hline $\mathrm{n}$ & $E_{n 1}$ & $E_{n 2}$ & $E_{n n}$ & $\frac{1}{n} \sum_{j=1}^{n} E_{n j}$ \\
\hline
\end{tabular}

The most common goals are based on either an "aggressive" or a "benevolent" peer-evaluation of DMUs. In the aggressive approach, the mean of efficiencies of the other DMUs is minimized in order to maximize the self-efficiency of the DMU under evaluation. The aim of the aggressive approach is to find optimal weights that make the evaluated DMU look the best that it can be and the remaining $n-1$ DMUs worse. In the benevolent approach, not only the efficiency of the evaluated DMU is maximized but also the mean efficiency of the remaining DMUs. In this formulation, the aim is to obtain weights that make both the DMU under evaluation and the remaining $n-1$ DMUs look as good as possible.

The aggressive evaluation DEA cross-efficiency model is formulated as follows

$$
\begin{gathered}
\min \sum_{r=1}^{s} u_{r k}\left(\sum_{j=1, j \neq k}^{n} y_{r j}\right)+u_{* k} \\
\text { s.t. } \quad \sum_{i=1}^{m} v_{i k}\left(\sum_{j=1, j \neq k}^{n} x_{i j}\right)=1 \\
\sum_{r=1}^{s} u_{r k} y_{r k}-E_{k k}^{*} \sum_{i=1}^{m} v_{i k} x_{i k}+u_{* k}=0 \quad j \neq k, j=1, \ldots, n \\
\sum_{r=1}^{s} u_{r k} y_{r j}-\sum_{i=1}^{m} v_{i k} x_{i j}+u_{* k} \leqslant 0 \\
u_{r k} \geqslant 0, v_{i j} \geqslant 0, u_{* k} \text { free, } \quad r=1, \ldots, s, \quad i=1, \ldots, m
\end{gathered}
$$

$E_{k k}$ is the optimal BCC self-evaluation of DMU $k$.

In the benevolent evaluation DEA cross-efficiency model, the objective function of model Equation (6) is changed from minimizing to maximizing.

\subsection{Step 3: the Aggregation of Different DEA Efficiency Scores Using the Shannon's Entropy Index}

In order to have a more comprehensive evaluation of the city ecological efficiency, the suggested method calculates the cross-efficiency measurements from different perspectives and approaches, running several DEA models. Even performing cross-efficiency analysis, any single DEA model has limited discriminatory power to generate an effective ranking of cities and, henceforth, it is useful to combine the results provided by several models integrating the different rankings of DMUs. 
Thus, to have a comprehensive measurement for the efficiencies, which takes into account various perspectives and approaches at the same time, the Shannon-DEA procedure as implemented by Bian and Yang [92] is adopted. This procedure is based on the calculation of the Shannon's entropy index that is used as a coefficient of importance degree [93,94]. Several scholars have showed that this comprehensive efficiency index discriminates better than individual DEA models to rank DMUs [92,94-96]. Furthermore, the aggregation based on the Shannon's entropy index of different efficiency measurements is better than the aggregation performed averaging the efficiency scores because it provides a Pareto optimal solution.

Bian and Yang [92] suggest a procedure that is based on six steps:

(1) Generation of an $n \times q$ efficiency matrix $E$ where $n$ is the number of DMUs and $q$ is the number of different DEA models performed. In matrix $E$, each row corresponds to a DMU and each column corresponds to a DEA cross-efficiency evaluation model. Therefore, as an example, $C E_{22}$ is the cross-efficiency score of DMU 2 obtained by performing DEA model 2.

(2) Normalization of the efficiency matrix $E$ recalculating the individual efficiencies as $e_{j p}=E_{j p} / \sum_{j=1}^{n} E_{j p}(p=1, \ldots, q$ and $j=1, \ldots, n)$

(3) Calculation of the Shannon's entropy index $H_{p}$ for each DEA model $p$ as $H_{p}=-(\ln n)^{-1} \sum_{j=1}^{n} e_{j p} \ln \left(e_{j p}\right)(p=1, \ldots, q$ and $j=1, \ldots, n)$

(4) Calculation of the diversification degree for every DEA model as $d_{p}=1-H_{p}(p=1, \ldots, q)$. The greater $d_{p}$, the greater the discriminatory power of the DEA model $p$. If a DEA model yields approximately equal efficiency scores for all DMUs, the DEA model has no discrimination ability for those DMUs, and the resulting $d_{p}$ has a small degree of importance. Accordingly, we can use $d_{p}$ to rate the importance of model $p$.

(5) Assessment of the importance degree of model $p$ by calculating the weights of every DEA model using $w_{p}=d_{p} / \sum_{p=1}^{q} d_{p}(p=1, \ldots, q)$ where $\sum_{p=1}^{q} w_{p}=1$

(6) Calculation of the cross-efficiency comprehensive index of DMU $j$ as $X E C I_{j}=\sum_{p=1}^{q} w_{p} E_{j p}(j=1, \ldots, n)$.

\begin{tabular}{cccc}
\hline & DEA Model 1 & DEA Model 2 & DEA Model q \\
\hline DMU 1 & $\mathrm{CE}_{11}$ & $\mathrm{CE}_{12}$ & $\mathrm{CE}_{1 q}$ \\
DMU 2 & $\mathrm{CE}_{21}$ & $\mathrm{CE}_{22}$ & $\mathrm{CE}_{2 q}$ \\
DMU $n$ & $\mathrm{CE}_{n 1}$ & $\mathrm{CE}_{n 2}$ & $\mathrm{CE}_{n q}$ \\
\hline
\end{tabular}

\section{Case Study}

The method for the calculation of the ecological efficiency index was used to perform a benchmarking study aimed at ranking and comparing Italian Province capital cities. The method was applied in two steps. In the first step, individual rankings were obtained by implementing seven DEA models, one calculating conventional DEA efficiency, and the remaining ones calculating cross-efficiency. In the second step, the six cross-efficiency models were combined together to get a single ranking by means of the Shannon's entropy index. Finally, results were compared with the ranking provided by Sole24Ore in 2011. This particular year was chosen because of data availability and reliability. The purpose of this comparison is not to identify the better ranking but rather to test the performance of the proposed method in terms of its discrimination capability. Indeed, relative rankings are generally influenced not only by the dataset, but also by the variables used in the model and the ranking methodology [97].

\subsection{Sample}

Italy is the fifth manufacturing economy in the world, with a population of about 57 million people that are concentrated on a relatively small territory. The intense industrial development on one side, and the high population density on the other side have lead to a strong environmental pressure making the environmental protection an important public concern. Even though much environmental 
progress has been achieved in the last decade, air pollution, traffic congestion, waste production, and excessive resource consumption still remain major problems.

In Italy, urban areas, and particularly cities and towns, have become very important to support policy actions aimed at improving environment quality. The Bassanini Act issued in 1997 strengthened the competence of local authorities as to environmental issues management. However, there are remarkable disparities across cities with respect to the capability of local governments to modify resource consumption patterns, waste management approaches, and the determinants of urban mobility towards more sustainable paths.

This study considers Italian Province capital cities as units of analysis. However, because of data unavailability, and missing values indeed being a major problem when DEA is performed, the sample size is limited to 116 capital cities.

\subsection{DEA Models}

Several DEA models were implemented to compute cross-efficiencies from different perspectives (i.e., arbitrary, aggressive and benevolent) as different models lead to different cross-efficiency scores. For all models, both input and output-orientations were chosen. In total, seven DEA models were performed. The assumption of variable returns to scale (VRS) was made because of the large variety of cities in terms of population and land area sizes, henceforth adopting the approach suggested by Banker et al. [85].

The first model (Model A) implemented conventional VRS DEA to evaluate cities ecological efficiencies. The other 6 models (Model A to Model G) implemented VRS cross-efficiency DEA and generated preliminary rankings of cities with respect to their ecological efficiency. Table 2 shows the DEA models adopted to carry on the study.

Table 2. Description of data envelopment analysis (DEA) models.

\begin{tabular}{ccccc}
\hline Model & Model Type & Orientation & Weight Computation & Approach \\
\hline Model A & conventional & output-oriented & 1 stage & - \\
Model B & cross-efficiency & output-oriented & 1 stage & arbitrary \\
Model C & cross-efficiency & input-oriented & 1 stage & arbitrary \\
Model D & cross-efficiency & output-oriented & 2 stage (secondary goal) & benevolent \\
Model E & cross-efficiency & output-oriented & 2 stage (secondary goal) & aggressive \\
Model F & cross-efficiency & input-oriented & 2 stage (secondary goal) & benevolent \\
Model G & cross-efficiency & input-oriented & 2 stage (secondary goal) & aggressive \\
\hline
\end{tabular}

\subsection{Variables}

Table 3 presents input and output variables used in the study to implement DEA models. As Thanassoulis [98] claims, the identification of input and output variables in DEA applications is both difficult and crucial. Thus, variables were identified having clearly in mind the purpose of the study and similar studies. However, as is common in studies like this, the selection of variables was influenced by data availability. Two inputs used in the analysis-the city population and territory land area-have been considered as non-discretionary or uncontrollable variables because they are not under control of the productive unit (i.e., the Province capital city), and cannot be controlled by the city council administrators (see, for instance, [99]). Even though the total city population and land area have been considered as uncontrollable variables in DEA models that cannot be controlled by the city decision makers, they are internal to the city production process. As these inputs are assumed to be part of the production process, they contribute to define the production possibility set (PPS) and the efficient frontier together with the discretionary inputs and the outputs. These production factors have been included in the models as suggested in the literature [100]. The uncontrollable inputs do not enter directly in the efficiency measures being optimized in the objective function of the DEA model. However, they can affect the efficiency measurements because of their inclusion in the constraints (see Appendix). 
Outputs are classified as either being "good" or "bad", whether they are desirable or undesirable. Because undesirable outputs are jointly produced with desirable outputs, as Yang and Pollit [101] (p. 1096) suggest: "[ . . . ] it makes sense for us to credit a DMU for its provision of desirable outputs and to penalize it for its production of emissions when evaluating its performance". In the presence of undesirable outputs, the DMUs having a larger amount of good (desirable) outputs and a lower amount of bad (undesirable) outputs relative to fewer inputs should be regarded as efficient [82]. Undesirable outputs were treated as inputs in the DEA models following literature [101-105]. Additionally, including the undesirable outputs as inputs in the DEA model is consistent with the measure of eco-efficiency indicated by the World Council for Sustainable Business Development as the ratio of the product/service value to the environmental influence [106].

Measurements for the variables were collected from the ISTAT database. Since 1996, ISTAT collects data relative to major Italian cities. The environmental issues investigated refer to the main following themes-air, energy, green areas, noise, transport, waste and water. Data relative to year 2011 have been used to calculate the city ecological efficiency index. In total, two inputs and 12 outputs (six desirable and six undesirable included as six further inputs) have been considered in the analysis.

Table 3. Input and output variables.

\begin{tabular}{|c|c|c|c|}
\hline Variable & Type & Classified as & Description \\
\hline DEPURATION & output & good & $\begin{array}{l}\text { amount of inhabitants living in the province } \\
\text { capital city served by black water depuration } \\
\text { service (year 2011) }\end{array}$ \\
\hline DWASTE & output & good & $\begin{array}{l}\text { amount of differentiated urban waste collected in } \\
\text { the province capital city (kg) (year 2011) }\end{array}$ \\
\hline PHOTOVOLTAICS & output & good & $\begin{array}{l}\text { total power of photovoltaic plants installed on } \\
\text { public building roofs }(\mathrm{kW}) \text { (year 2011) }\end{array}$ \\
\hline GREEN & output & good & $\begin{array}{l}\text { total amount of urban green available to } \\
\text { citizens (square m) (year 2011) }\end{array}$ \\
\hline TRANSPORTATION & output & good & $\begin{array}{l}\text { demand for public transportation } \\
\text { (no. of passengers) (year 2011) }\end{array}$ \\
\hline NPCARS & output & good & $\begin{array}{l}\text { no. of cars owned by people living in the } \\
\text { province capital city classified as } \\
\text { euro IV and euro V (year 2011) }\end{array}$ \\
\hline WATER & output & bad & $\begin{array}{l}\text { household water consumption } \\
\text { (liters per day) (year 2011) }\end{array}$ \\
\hline NDWASTE & output & bad & $\begin{array}{l}\text { amount of not differentiated urban waste } \\
\text { collected }(\mathrm{kg}) \text { (year 2011) }\end{array}$ \\
\hline GAS & output & bad & $\begin{array}{l}\text { household natural gas consumption (cooking } \\
\text { and heating) (cubic meters) (year 2011) }\end{array}$ \\
\hline ELECTRICITY & output & bad & $\begin{array}{l}\text { household electricity } \\
\text { consumption (kWh) (year 2011) }\end{array}$ \\
\hline POLLUTION & output & bad & $\begin{array}{l}\text { exceedance days of air quality threshold value of } \\
\text { PM10 (year 2011) }\end{array}$ \\
\hline PCARS & output & bad & $\begin{array}{l}\text { no. of cars owned by people living in the } \\
\text { province capital city classified as euro 0-III } \\
\text { (polluting cars) (year 2011) }\end{array}$ \\
\hline POPULATION & input & non discretionary & $\begin{array}{l}\text { total population living in the province } \\
\text { capital city (year 2011) }\end{array}$ \\
\hline AREA & input & non discretionary & total city land area (squared km) (year 2011) \\
\hline
\end{tabular}

\subsection{Results}

Table 4 displays efficiency scores calculated by implementing DEA Models A-G, the efficiency score computed as a comprehensive measurement by using the Shannon's entropy index (XECI), and the measurements relative to environmental quality used by Sole24Ore to construct the city 
livability index. Additionally, Table 4 shows the ranking levels of cities for every model, too. As it has been emphasized in the second section of this paper, the Sole24Ore index has a large amount of subjectivity determined by the arbitrary choice of the set of weights utilized to combine and group 25 indicators of environmental quality into seven macro-indicators that are finally aggregated to get an individual index of environmental quality by adopting a further set of weights. For instance, for the aggregation of the depuration, water consumption, and water dispersion indicators related to the water macro-indicator, the weights of six, 3.5 and 2.5 are adopted. Moreover, the indicators are normalized by using certain utility functions that are developed taking into account some sustainability goals. In this way, scores given to indicators provide a measurement of the sustainability rate of a city when it is compared to an ideal city.

Model A has 70 full (100\%) efficient cities and a large number of cities having their efficiency scores higher than $90 \%$. Efficiencies are between $51.6 \%$ and $100 \%$, while mean efficiency is $96.5 \%$, and standard deviation is only $7.4 \%$. Model A thus remains useless to rank cities with respect to their ecological efficiency because of its scarce discrimination power. On the contrary, models from Model A to Model $G$ which are based on the computation of the cross-efficiency score offer a better discriminatory power. Indeed, the minimum efficiency score decreases from 51.6\% (Model A) to 7.0\% (Model D), and is never higher than 13.5\% (Model G). These models have a higher standard deviation measurement than Model A, confirming their greater discriminatory capability. The analysis of the ranking levels emerging from the cross-efficiency calculation supports the idea that Model A is the worst one. Indeed, this model is able to identify only 39 ranks. The adoption of the cross-efficiency method largely increases the number of ranking levels. The model that calculates ecological efficiency by utilizing the Shannon's entropy index (XECI model) behaves slightly better than the previous DEA cross-efficiency models, as it identifies 103 ranks. This model behaves even better than the index computed by the Sole24Ore which identifies only 90 ranking levels while covers 107 cities. Thus, there is no indication that the ranking provided by the Sole24Ore is particularly discriminating.

According to the XECI model, mean ecological efficiency relative to cities in sample is $60.91 \%$, the maximum efficiency is $84.21 \%$ and the minimum efficiency is only $11.05 \%$. Forty-seven cities achieve an ecological efficiency score which is below average. Moreover, among cities that are placed in the first 10 positions of the ranking, four of them are located in the North of Italy (Aosta, Genova, Milano and Trento), three in the Center of Italy (Livorno, Prato and Roma), two in the Isles (Oristano and Tortolì) and only one in the South (Salerno), even though this latter achieves the higher level in the ranking with the score of $84.21 \%$. These results are not unexpected. Indeed, in the last decade Salerno has become one of the excellent and more livable cities in Southern Italy. Since 2006, the local government has implemented a well-organized and efficient solid waste management, with the doorstep collection of waste, a high rate of recycling, and a strong involvement of the population. In addition, since the middle of the 90s, the city administration has largely invested to improve urban quality and increase the attractiveness of the city internationally. The local governments of Aosta, Genova, Milano and Trento have also adopted good practices to improve the quality of environment and sustainability. They all approved the Plan for Green and/or have implemented Local Agenda 21, while Milano, Trento and Genova implemented the Urban Mobility and Logistics Plan and an Infomobility System aimed at reducing traffic congestion. Trento made a great effort to support the installation of renewable solar facilities and the usage of public transportation, particularly by public employees going at work. Even though the city of Milano did a limited investment to install renewable energy plants on the roofs of public buildings, the local government promoted the adoption of design methods and construction materials improving energy efficiency of public and private buildings. This practice allowed having an important reduction of natural gas consumption. 
Table 4. Efficiency scores.

\begin{tabular}{|c|c|c|c|c|c|c|c|c|c|c|c|c|c|c|c|c|c|c|c|}
\hline \multirow{2}{*}{ DMU } & \multirow{2}{*}{$\begin{array}{c}\text { Province } \\
\text { Capital Cities }\end{array}$} & \multicolumn{2}{|c|}{ Model A } & \multicolumn{2}{|c|}{ Model B } & \multicolumn{2}{|c|}{ Model C } & \multicolumn{2}{|c|}{ Model D } & \multicolumn{2}{|c|}{ Model E } & \multicolumn{2}{|c|}{ Model F } & \multicolumn{2}{|c|}{ Model G } & \multicolumn{2}{|c|}{ XECI } & \multicolumn{2}{|c|}{ Sole24Ore } \\
\hline & & Eff & Rank & Eff & Rank & Eff & Rank & Eff & Rank & Eff & Rank & Eff & Rank & Eff & Rank & Eff & Rank & Index & Rank \\
\hline CI1 & Agrigento & 0.884 & 26 & 0.338 & 90 & 0.391 & 92 & 0.532 & 86 & 0.303 & 91 & 0.477 & 93 & 0.382 & 90 & 0.4027 & 97 & 0.327 & 75 \\
\hline $\mathrm{CI} 2$ & Alessandria & 0.865 & 30 & 0.472 & 77 & 0.513 & 79 & 0.737 & 68 & 0.423 & 78 & 0.639 & 74 & 0.521 & 77 & 0.5497 & 83 & 0.462 & 54 \\
\hline $\mathrm{CI} 3$ & Ancona & 0.975 & 12 & 0.565 & 40 & 0.630 & 35 & 0.851 & 29 & 0.507 & 40 & 0.781 & 22 & 0.633 & 32 & 0.6597 & 34 & 0.527 & 33 \\
\hline CI4 & Andria & 1.000 & 1 & 0.535 & 52 & 0.627 & 36 & 0.833 & 36 & 0.469 & 61 & 0.762 & 32 & 0.597 & 45 & 0.6355 & 43 & & - \\
\hline CI5 & Aosta & 1.000 & 1 & 0.740 & 3 & 0.816 & 3 & 0.980 & 1 & 0.719 & 2 & 0.958 & 1 & 0.829 & 1 & 0.8391 & 2 & 0.593 & 14 \\
\hline CI6 & Arezzo & 0.869 & 29 & 0.461 & 80 & 0.519 & 77 & 0.695 & 76 & 0.394 & 83 & 0.629 & 77 & 0.506 & 77 & 0.5324 & 86 & 0.449 & 59 \\
\hline CI7 & Ascoli Piceno & 0.950 & 17 & 0.473 & 76 & 0.527 & 74 & 0.776 & 60 & 0.422 & 79 & 0.661 & 65 & 0.531 & 73 & 0.5638 & 78 & 0.537 & 30 \\
\hline CI8 & Asti & 0.989 & 7 & 0.526 & 56 & 0.566 & 60 & 0.832 & 37 & 0.479 & 57 & 0.713 & 47 & 0.578 & 54 & 0.6144 & 57 & 0.447 & 61 \\
\hline CI10 & Bari & 1.000 & 1 & 0.669 & 11 & 0.693 & 18 & 0.892 & 12 & 0.605 & 10 & 0.796 & 20 & 0.688 & 16 & 0.7230 & 15 & 0.442 & 65 \\
\hline CI11 & Barletta & 1.000 & 1 & 0.574 & 36 & 0.677 & 23 & 0.861 & 24 & 0.509 & 38 & 0.819 & 14 & 0.657 & 25 & 0.6811 & 28 & - & - \\
\hline CI12 & Belluno & 1.000 & 1 & 0.365 & 88 & 0.422 & 90 & 0.470 & 90 & 0.303 & 91 & 0.481 & 92 & 0.413 & 88 & 0.4078 & 95 & 0.693 & 2 \\
\hline CI13 & Benevento & 0.833 & 33 & 0.198 & 95 & 0.212 & 97 & 0.224 & 95 & 0.176 & 96 & 0.249 & 99 & 0.219 & 94 & 0.2124 & 102 & 0.507 & 40 \\
\hline CI14 & Bergamo & 1.000 & 1 & 0.576 & 35 & 0.598 & 47 & 0.856 & 26 & 0.549 & 28 & 0.722 & 44 & 0.615 & 39 & 0.6516 & 36 & 0.521 & 35 \\
\hline CI15 & Biella & 0.992 & 4 & 0.515 & 62 & 0.546 & 69 & 0.825 & 41 & 0.487 & 52 & 0.684 & 58 & 0.568 & 58 & 0.6029 & 61 & 0.468 & 52 \\
\hline CI16 & Bologna & 1.000 & 1 & 0.661 & 14 & 0.694 & 17 & 0.898 & 10 & 0.604 & 11 & 0.822 & 12 & 0.688 & 16 & 0.7267 & 13 & 0.600 & 11 \\
\hline CI17 & Bolzano & 1.000 & 1 & 0.651 & 17 & 0.702 & 14 & 0.891 & 13 & 0.593 & 18 & 0.811 & 17 & 0.704 & 13 & 0.7240 & 14 & 0.666 & 4 \\
\hline CI18 & Brescia & 1.000 & 1 & 0.641 & 18 & 0.682 & 21 & 0.907 & 8 & 0.585 & 21 & 0.813 & 16 & 0.683 & 18 & 0.7173 & 18 & 0.496 & 43 \\
\hline CI19 & Brindisi & 1.000 & 1 & 0.570 & 38 & 0.655 & 29 & 0.854 & 27 & 0.492 & 48 & 0.781 & 22 & 0.627 & 34 & 0.6612 & 33 & 0.445 & 63 \\
\hline $\mathrm{CI} 21$ & Caltanissetta & 0.760 & 36 & 0.371 & 87 & 0.412 & 91 & 0.612 & 84 & 0.327 & 89 & 0.500 & 91 & 0.401 & 89 & 0.4362 & 93 & 0.321 & 76 \\
\hline CI22 & Campobasso & 1.000 & 1 & 0.480 & 74 & 0.565 & 61 & 0.784 & 58 & 0.435 & 74 & 0.698 & 53 & 0.567 & 59 & 0.5864 & 69 & 0.499 & 42 \\
\hline $\mathrm{CI} 23$ & Carbonia & 1.000 & 1 & 0.718 & 7 & 0.791 & 5 & 0.779 & 59 & 0.597 & 16 & 0.757 & 35 & 0.746 & 9 & 0.7295 & 12 & 0.496 & 43 \\
\hline CI24 & Caserta & 1.000 & 1 & 0.608 & 24 & 0.677 & 23 & 0.879 & 17 & 0.555 & 27 & 0.804 & 19 & 0.676 & 21 & 0.6983 & 23 & 0.476 & 50 \\
\hline $\mathrm{CI} 25$ & Catania & 1.000 & 1 & 0.250 & 94 & 0.215 & 96 & 0.244 & 94 & 0.197 & 95 & 0.206 & 100 & 0.215 & 95 & 0.2210 & 101 & 0.286 & 81 \\
\hline $\mathrm{CI} 26$ & Catanzaro & 1.000 & 1 & 0.499 & 71 & 0.513 & 79 & 0.668 & 81 & 0.459 & 65 & 0.559 & 88 & 0.511 & 76 & 0.5343 & 85 & 0.307 & 79 \\
\hline CI27 & Chieti & 0.796 & 35 & 0.500 & 70 & 0.545 & 70 & 0.705 & 73 & 0.442 & 72 & 0.629 & 77 & 0.551 & 66 & 0.5606 & 79 & 0.540 & 28 \\
\hline CI28 & Como & 0.993 & 3 & 0.534 & 53 & 0.554 & 67 & 0.829 & 38 & 0.508 & 39 & 0.678 & 61 & 0.574 & 55 & 0.6119 & 58 & 0.459 & 57 \\
\hline CI29 & Cosenza & 0.942 & 18 & 0.477 & 75 & 0.532 & 72 & 0.759 & 65 & 0.453 & 66 & 0.668 & 64 & 0.539 & 71 & 0.5701 & 73 & 0.424 & 68 \\
\hline CI30 & Cremona & 0.990 & 6 & 0.507 & 66 & 0.532 & 72 & 0.816 & 44 & 0.471 & 60 & 0.657 & 68 & 0.551 & 66 & 0.5878 & 67 & 0.517 & 36 \\
\hline CI31 & Crotone & 0.914 & 23 & 0.460 & 81 & 0.513 & 79 & 0.721 & 71 & 0.407 & 81 & 0.598 & 83 & 0.503 & 79 & 0.5322 & 86 & 0.232 & 87 \\
\hline CI32 & Cuneo & 0.959 & 15 & 0.547 & 46 & 0.607 & 44 & 0.826 & 40 & 0.480 & 56 & 0.734 & 40 & 0.610 & 41 & 0.6322 & 46 & 0.589 & 15 \\
\hline CI33 & Enna & 0.698 & 38 & 0.305 & 92 & 0.350 & 93 & 0.531 & 87 & 0.272 & 93 & 0.421 & 95 & 0.338 & 91 & 0.3687 & 98 & 0.278 & 82 \\
\hline CI34 & Fermo & 0.935 & 20 & 0.471 & 78 & 0.524 & 76 & 0.762 & 64 & 0.418 & 80 & 0.643 & 72 & 0.530 & 74 & 0.5565 & 81 & - & - \\
\hline CI35 & Ferrara & 0.877 & 27 & 0.532 & 54 & 0.560 & 63 & 0.770 & 62 & 0.452 & 67 & 0.658 & 67 & 0.559 & 62 & 0.5872 & 68 & 0.562 & 21 \\
\hline
\end{tabular}


Table 4. Cont.

\begin{tabular}{|c|c|c|c|c|c|c|c|c|c|c|c|c|c|c|c|c|c|c|c|}
\hline \multirow{2}{*}{ DMU } & \multirow{2}{*}{$\begin{array}{c}\text { Province } \\
\text { Capital } \\
\text { Cities } \\
\end{array}$} & \multicolumn{2}{|c|}{ Model A } & \multicolumn{2}{|c|}{ Model B } & \multicolumn{2}{|c|}{ Model C } & \multicolumn{2}{|c|}{ Model D } & \multicolumn{2}{|c|}{ Model E } & \multicolumn{2}{|c|}{ Model F } & \multicolumn{2}{|c|}{ Model G } & \multicolumn{2}{|c|}{ XECI } & \multicolumn{2}{|c|}{ Sole24Ore } \\
\hline & & Eff & Rank & Eff & Rank & Eff & Rank & Eff & Rank & Eff & Rank & Eff & Rank & Eff & Rank & Eff & Rank & Index & Rank \\
\hline CI36 & Firenze & 1.000 & 1 & 0.567 & 39 & 0.591 & 51 & 0.702 & 74 & 0.520 & 35 & 0.687 & 57 & 0.587 & 51 & 0.6080 & 60 & 0.509 & 39 \\
\hline CI37 & Foggia & 1.000 & 1 & 0.543 & 48 & 0.624 & 37 & 0.834 & 35 & 0.475 & 59 & 0.751 & 37 & 0.589 & 50 & 0.6347 & 44 & 0.460 & 56 \\
\hline CI38 & Forlì & 1.000 & 1 & 0.585 & 32 & 0.627 & 36 & 0.803 & 50 & 0.500 & 45 & 0.734 & 40 & 0.627 & 34 & 0.6444 & 41 & 0.595 & 13 \\
\hline CI39 & Frosinone & 0.844 & 32 & 0.397 & 85 & 0.422 & 90 & 0.678 & 80 & 0.380 & 84 & 0.563 & 87 & 0.438 & 86 & 0.4789 & 89 & 0.273 & 83 \\
\hline CI40 & Genova & 1.000 & 1 & 0.694 & 9 & 0.721 & 11 & 0.891 & 13 & 0.621 & 9 & 0.839 & 9 & 0.710 & 10 & 0.7448 & 9 & 0.570 & 19 \\
\hline CI41 & Gorizia & 0.935 & 20 & 0.536 & 51 & 0.592 & 50 & 0.772 & 61 & 0.499 & 46 & 0.710 & 48 & 0.608 & 42 & 0.6179 & 54 & 0.533 & 32 \\
\hline CI42 & Grosseto & 1.000 & 1 & 0.628 & 21 & 0.671 & 24 & 0.858 & 25 & 0.526 & 32 & 0.757 & 35 & 0.630 & 33 & 0.6772 & 29 & 0.445 & 63 \\
\hline CI43 & Iglesias & 1.000 & 1 & 0.398 & 84 & 0.476 & 85 & 0.569 & 85 & 0.362 & 87 & 0.519 & 89 & 0.465 & 81 & 0.4636 & 92 & 0.496 & 43 \\
\hline CI44 & Imperia & 0.516 & 39 & 0.115 & 96 & 0.130 & 98 & 0.070 & 96 & 0.099 & 97 & 0.116 & 101 & 0.135 & 96 & 0.1105 & 103 & 0.314 & 77 \\
\hline CI45 & Isernia & 1.000 & 1 & 0.477 & 75 & 0.562 & 62 & 0.719 & 72 & 0.460 & 64 & 0.620 & 80 & 0.552 & 65 & 0.5639 & 78 & 0.312 & 78 \\
\hline CI46 & La Spezia & 1.000 & 1 & 0.610 & 23 & 0.693 & 18 & 0.825 & 41 & 0.549 & 28 & 0.806 & 18 & 0.681 & 19 & 0.6922 & 26 & 0.636 & 5 \\
\hline CI47 & Lanusei & 1.000 & 1 & 0.514 & 63 & 0.645 & 31 & 0.784 & 58 & 0.488 & 51 & 0.697 & 54 & 0.644 & 29 & 0.6268 & 49 & - & - \\
\hline CI48 & L'Aquila & 1.000 & 1 & 0.583 & 33 & 0.609 & 43 & 0.692 & 77 & 0.479 & 57 & 0.735 & 39 & 0.572 & 56 & 0.6104 & 59 & 0.365 & 72 \\
\hline CI49 & Latina & 0.979 & 10 & 0.560 & 42 & 0.599 & 46 & 0.844 & 31 & 0.486 & 53 & 0.715 & 46 & 0.593 & 49 & 0.6315 & 47 & 0.289 & 80 \\
\hline CI50 & Lecce & 0.980 & 9 & 0.485 & 73 & 0.525 & 75 & 0.799 & 52 & 0.430 & 76 & 0.643 & 72 & 0.523 & 76 & 0.5662 & 76 & 0.448 & 60 \\
\hline CI51 & Lecco & 0.999 & 2 & 0.520 & 59 & 0.569 & 59 & 0.826 & 40 & 0.483 & 55 & 0.698 & 53 & 0.586 & 52 & 0.6123 & 58 & 0.441 & 66 \\
\hline CI52 & Livorno & 1.000 & 1 & 0.723 & 6 & 0.789 & 6 & 0.920 & 6 & 0.634 & 6 & 0.905 & 6 & 0.766 & 8 & 0.7877 & 6 & 0.537 & 30 \\
\hline CI53 & Lodi & 1.000 & 1 & 0.502 & 69 & 0.518 & 78 & 0.794 & 54 & 0.485 & 54 & 0.641 & 73 & 0.541 & 70 & 0.5794 & 71 & 0.568 & 20 \\
\hline CI54 & Lucca & 0.874 & 28 & 0.507 & 66 & 0.541 & 71 & 0.736 & 69 & 0.443 & 71 & 0.643 & 72 & 0.549 & 68 & 0.5685 & 75 & 0.545 & 27 \\
\hline CI55 & Macerata & 0.731 & 37 & 0.396 & 86 & 0.448 & 88 & 0.621 & 83 & 0.359 & 88 & 0.564 & 86 & 0.455 & 83 & 0.4725 & 90 & 0.584 & 16 \\
\hline CI56 & Mantova & 1.000 & 1 & 0.477 & 75 & 0.494 & 81 & 0.799 & 52 & 0.446 & 69 & 0.630 & 76 & 0.517 & 74 & 0.5596 & 80 & 0.595 & 13 \\
\hline CI57 & Massa & 0.940 & 19 & 0.557 & 44 & 0.590 & 52 & 0.803 & 50 & 0.485 & 54 & 0.672 & 63 & 0.594 & 48 & 0.6153 & 56 & 0.307 & 79 \\
\hline CI58 & Matera & 1.000 & 1 & 0.696 & 8 & 0.695 & 16 & 0.875 & 19 & 0.601 & 13 & 0.780 & 23 & 0.679 & 20 & 0.7202 & 17 & 0.448 & 60 \\
\hline CI59 & Messina & 1.000 & 1 & 0.595 & 27 & 0.594 & 49 & 0.789 & 55 & 0.532 & 30 & 0.649 & 71 & 0.589 & 50 & 0.6238 & 50 & 0.162 & 90 \\
\hline CI60 & Milano & 1.000 & 1 & 0.773 & 2 & 0.796 & 4 & 0.948 & 4 & 0.699 & 3 & 0.910 & 5 & 0.769 & 7 & 0.8149 & 3 & 0.501 & 41 \\
\hline CI61 & Modena & 1.000 & 1 & 0.628 & 21 & 0.666 & 25 & 0.895 & 11 & 0.558 & 25 & 0.795 & 21 & 0.671 & 24 & 0.7006 & 21 & 0.527 & 33 \\
\hline CI62 & Monza & 1.000 & 1 & 0.596 & 26 & 0.632 & 34 & 0.872 & 21 & 0.593 & 18 & 0.777 & 25 & 0.647 & 28 & 0.6853 & 27 & - & - \\
\hline CI63 & Napoli & 1.000 & 1 & 0.652 & 16 & 0.665 & 26 & 0.828 & 39 & 0.603 & 12 & 0.760 & 34 & 0.654 & 27 & 0.6929 & 25 & 0.360 & 73 \\
\hline CI64 & Novara & 1.000 & 1 & 0.581 & 34 & 0.612 & 42 & 0.838 & 34 & 0.522 & 33 & 0.731 & 41 & 0.623 & 35 & 0.6499 & 37 & 0.445 & 63 \\
\hline CI65 & Nuoro & 1.000 & 1 & 0.473 & 76 & 0.480 & 84 & 0.409 & 91 & 0.376 & 85 & 0.407 & 96 & 0.442 & 85 & 0.4305 & 94 & 0.554 & 25 \\
\hline CI66 & Olbia & 1.000 & 1 & 0.576 & 35 & 0.597 & 48 & 0.819 & 42 & 0.492 & 48 & 0.655 & 69 & 0.594 & 48 & 0.6207 & 52 & 0.515 & 37 \\
\hline CI67 & Oristano & 1.000 & 1 & 0.672 & 10 & 0.779 & 8 & 0.891 & 13 & 0.600 & 14 & 0.871 & 7 & 0.770 & 6 & 0.7616 & 8 & 0.525 & 34 \\
\hline CI68 & Padova & 1.000 & 1 & 0.633 & 20 & 0.644 & 32 & 0.865 & 23 & 0.603 & 12 & 0.773 & 27 & 0.654 & 27 & 0.6945 & 24 & 0.535 & 31 \\
\hline CI69 & Palermo & 1.000 & 1 & 0.327 & 91 & 0.322 & 94 & 0.394 & 92 & 0.290 & 92 & 0.359 & 97 & 0.319 & 92 & 0.3350 & 99 & 0.235 & 86 \\
\hline CI70 & Parma & 1.000 & 1 & 0.567 & 39 & 0.622 & 38 & 0.851 & 29 & 0.498 & 47 & 0.761 & 33 & 0.622 & 36 & 0.6518 & 36 & 0.619 & 8 \\
\hline CI71 & Pavia & 0.975 & 12 & 0.477 & 75 & 0.493 & 82 & 0.786 & 56 & 0.440 & 73 & 0.610 & 81 & 0.512 & 75 & 0.5520 & 82 & 0.485 & 48 \\
\hline CI72 & Perugia & 0.959 & 15 & 0.608 & 24 & 0.647 & 30 & 0.839 & 33 & 0.506 & 41 & 0.764 & 30 & 0.630 & 33 & 0.6643 & 31 & 0.615 & 9 \\
\hline
\end{tabular}


Table 4. Cont

\begin{tabular}{|c|c|c|c|c|c|c|c|c|c|c|c|c|c|c|c|c|c|c|c|}
\hline \multirow{2}{*}{ DMU } & \multirow{2}{*}{$\begin{array}{c}\text { Province Capital } \\
\text { Cities }\end{array}$} & \multicolumn{2}{|c|}{ Model A } & \multicolumn{2}{|c|}{ Model B } & \multicolumn{2}{|c|}{ Model C } & \multicolumn{2}{|c|}{ Model D } & \multicolumn{2}{|c|}{ Model E } & \multicolumn{2}{|c|}{ Model F } & \multicolumn{2}{|c|}{ Model G } & \multicolumn{2}{|c|}{ XECI } & \multicolumn{2}{|c|}{ Sole24Ore } \\
\hline & & Eff & Rank & Eff & Rank & Eff & Rank & Eff & Rank & Eff & Rank & Eff & Rank & Eff & Rank & Eff & Rank & Index & Rank \\
\hline $\mathrm{CI} 73$ & Pesaro & 0.874 & 28 & 0.558 & 43 & 0.598 & 46 & 0.779 & 59 & 0.489 & 50 & 0.702 & 51 & 0.602 & 43 & 0.6198 & 53 & 0.561 & 22 \\
\hline CI74 & Pescara & 0.988 & 8 & 0.517 & 61 & 0.548 & 68 & 0.753 & 67 & 0.503 & 44 & 0.661 & 65 & 0.556 & 63 & 0.5887 & 66 & 0.425 & 67 \\
\hline CI75 & Piacenza & 0.991 & 5 & 0.590 & 29 & 0.624 & 37 & 0.868 & 22 & 0.529 & 31 & 0.745 & 38 & 0.636 & 31 & 0.6641 & 31 & 0.538 & 29 \\
\hline CI76 & Pisa & 0.814 & 34 & 0.471 & 78 & 0.499 & 80 & 0.699 & 75 & 0.405 & 82 & 0.586 & 84 & 0.504 & 78 & 0.5259 & 87 & 0.596 & 12 \\
\hline CI77 & Pistoia & 1.000 & 1 & 0.468 & 79 & 0.472 & 86 & 0.530 & 88 & 0.394 & 83 & 0.514 & 90 & 0.448 & 84 & 0.4701 & 91 & 0.457 & 58 \\
\hline CI78 & Pordenone & 1.000 & 1 & 0.522 & 57 & 0.529 & 73 & 0.654 & 82 & 0.520 & 35 & 0.623 & 79 & 0.550 & 67 & 0.5659 & 77 & 0.620 & 7 \\
\hline CI79 & Potenza & 1.000 & 1 & 0.587 & 30 & 0.615 & 40 & 0.826 & 40 & 0.517 & 36 & 0.717 & 45 & 0.619 & 37 & 0.6455 & 39 & 0.461 & 55 \\
\hline CI80 & Prato & 1.000 & 1 & 0.724 & 5 & 0.787 & 7 & 0.949 & 3 & 0.656 & 4 & 0.929 & 2 & 0.776 & 5 & 0.8018 & 4 & 0.537 & 30 \\
\hline CI81 & Ragusa & 0.990 & 6 & 0.513 & 64 & 0.571 & 57 & 0.809 & 46 & 0.448 & 68 & 0.682 & 60 & 0.548 & 69 & 0.5938 & 64 & 0.446 & 62 \\
\hline CI82 & Ravenna & 1.000 & 1 & 0.571 & 37 & 0.580 & 55 & 0.828 & 39 & 0.478 & 58 & 0.675 & 62 & 0.583 & 53 & 0.6178 & 54 & 0.557 & 23 \\
\hline CI83 & Reggio Calabria & 1.000 & 1 & 0.564 & 41 & 0.570 & 58 & 0.754 & 66 & 0.492 & 48 & 0.626 & 78 & 0.566 & 60 & 0.5945 & 64 & 0.222 & 88 \\
\hline $\mathrm{CI} 84$ & Reggio Emilia & 1.000 & 1 & 0.601 & 25 & 0.647 & 30 & 0.806 & 48 & 0.521 & 34 & 0.763 & 31 & 0.644 & 29 & 0.6621 & 32 & 0.605 & 10 \\
\hline CI85 & Rieti & 0.852 & 31 & 0.412 & 83 & 0.460 & 87 & 0.684 & 79 & 0.362 & 86 & 0.571 & 85 & 0.456 & 82 & 0.4896 & 88 & 0.513 & 38 \\
\hline CI86 & Rimini & 1.000 & 1 & 0.665 & 13 & 0.699 & 15 & 0.916 & 7 & 0.591 & 19 & 0.820 & 13 & 0.708 & 11 & 0.7317 & 11 & 0.556 & 24 \\
\hline CI87 & Roma & 1.000 & 1 & 0.740 & 3 & 0.705 & 13 & 0.887 & 14 & 0.656 & 4 & 0.779 & 24 & 0.685 & 17 & 0.7416 & 10 & 0.457 & 58 \\
\hline $\mathrm{CI} 88$ & Rovigo & 0.952 & 16 & 0.503 & 68 & 0.545 & 70 & 0.789 & 55 & 0.465 & 62 & 0.683 & 59 & 0.564 & 61 & 0.5904 & 65 & 0.367 & 71 \\
\hline CI89 & Salerno & 1.000 & 1 & 0.816 & 1 & 0.820 & 2 & 0.963 & 2 & 0.732 & 1 & 0.911 & 4 & 0.817 & 3 & 0.8421 & 1 & 0.473 & 51 \\
\hline CI90 & Sanluri & 1.000 & 1 & 0.544 & 47 & 0.723 & 10 & 0.804 & 49 & 0.490 & 49 & 0.755 & 36 & 0.694 & 15 & 0.6657 & 30 & - & - \\
\hline CI91 & Sassari & 1.000 & 1 & 0.733 & 4 & 0.735 & 9 & 0.851 & 29 & 0.599 & 15 & 0.761 & 33 & 0.671 & 24 & 0.7241 & 14 & 0.515 & 37 \\
\hline CI92 & Savona & 0.980 & 9 & 0.517 & 61 & 0.597 & 48 & 0.817 & 43 & 0.464 & 63 & 0.725 & 42 & 0.593 & 49 & 0.6172 & 55 & 0.556 & 24 \\
\hline CI93 & Siena & 1.000 & 1 & 0.665 & 13 & 0.720 & 12 & 0.884 & 15 & 0.556 & 26 & 0.811 & 17 & 0.700 & 14 & 0.7211 & 16 & 0.488 & 47 \\
\hline CI94 & Siracusa & 1.000 & 1 & 0.455 & 82 & 0.488 & 83 & 0.800 & 51 & 0.425 & 77 & 0.637 & 75 & 0.490 & 80 & 0.5482 & 84 & 0.262 & 84 \\
\hline CI95 & Sondrio & 1.000 & 1 & 0.542 & 49 & 0.570 & 58 & 0.826 & 40 & 0.569 & 24 & 0.703 & 50 & 0.598 & 44 & 0.6340 & 45 & 0.582 & 17 \\
\hline CI96 & Taranto & 0.907 & 24 & 0.487 & 72 & 0.545 & 70 & 0.763 & 63 & 0.433 & 75 & 0.660 & 66 & 0.534 & 72 & 0.5689 & 74 & 0.357 & 74 \\
\hline CI97 & Tempio Pausania & 1.000 & 1 & 0.347 & 89 & 0.437 & 89 & 0.498 & 89 & 0.305 & 90 & 0.445 & 94 & 0.422 & 87 & 0.4075 & 96 & 0.515 & 37 \\
\hline CI98 & Teramo & 0.999 & 2 & 0.556 & 45 & 0.616 & 39 & 0.840 & 32 & 0.487 & 52 & 0.745 & 38 & 0.615 & 39 & 0.6412 & 42 & 0.490 & 46 \\
\hline CI99 & Terni & 0.905 & 25 & 0.521 & 58 & 0.569 & 59 & 0.785 & 57 & 0.460 & 64 & 0.706 & 49 & 0.572 & 56 & 0.6005 & 62 & 0.547 & 26 \\
\hline CI100 & Torino & 1.000 & 1 & 0.669 & 11 & 0.659 & 28 & 0.901 & 9 & 0.633 & 7 & 0.772 & 28 & 0.671 & 24 & 0.7169 & 18 & 0.495 & 44 \\
\hline CI101 & Tortolì & 1.000 & 1 & 0.668 & 12 & 0.839 & 1 & 0.874 & 20 & 0.655 & 5 & 0.852 & 8 & 0.819 & 2 & 0.7824 & 7 & - & - \\
\hline CI102 & Trani & 1.000 & 1 & 0.518 & 60 & 0.602 & 45 & 0.826 & 40 & 0.464 & 63 & 0.735 & 39 & 0.596 & 46 & 0.6218 & 51 & - & - \\
\hline
\end{tabular}


Table 4. Cont.

\begin{tabular}{|c|c|c|c|c|c|c|c|c|c|c|c|c|c|c|c|c|c|c|c|}
\hline \multirow{2}{*}{ DMU } & \multirow{2}{*}{$\begin{array}{c}\text { Province } \\
\text { Capital Cities }\end{array}$} & \multicolumn{2}{|c|}{ Model A } & \multicolumn{2}{|c|}{ Model B } & \multicolumn{2}{|c|}{ Model C } & \multicolumn{2}{|c|}{ Model D } & \multicolumn{2}{|c|}{ Model E } & \multicolumn{2}{|c|}{ Model F } & \multicolumn{2}{|c|}{ Model G } & \multicolumn{2}{|c|}{ XECI } & \multicolumn{2}{|c|}{ Sole24Ore } \\
\hline & & Eff & Rank & Eff & Rank & Eff & Rank & Eff & Rank & Eff & Rank & Eff & Rank & Eff & Rank & Eff & Rank & Index & Rank \\
\hline CI103 & Trapani & 0.918 & 22 & 0.511 & 65 & 0.559 & 64 & 0.723 & 70 & 0.443 & 71 & 0.609 & 82 & 0.526 & 75 & 0.5605 & 79 & 0.240 & 85 \\
\hline CI104 & Trento & 1.000 & 1 & 0.733 & 4 & 0.787 & 7 & 0.940 & 5 & 0.631 & 8 & 0.928 & 3 & 0.784 & 4 & 0.7985 & 5 & 0.682 & 3 \\
\hline CI105 & Treviso & 0.928 & 21 & 0.272 & 93 & 0.275 & 95 & 0.318 & 93 & 0.261 & 94 & 0.311 & 98 & 0.290 & 93 & 0.2878 & 100 & 0.465 & 53 \\
\hline CI106 & Trieste & 0.972 & 13 & 0.564 & 41 & 0.614 & 41 & 0.840 & 32 & 0.505 & 42 & 0.745 & 38 & 0.611 & 40 & 0.6451 & 40 & 0.492 & 45 \\
\hline CI107 & Udine & 1.000 & 1 & 0.586 & 31 & 0.594 & 49 & 0.838 & 34 & 0.538 & 29 & 0.695 & 55 & 0.617 & 38 & 0.6438 & 41 & 0.577 & 18 \\
\hline CI108 & Varese & 1.000 & 1 & 0.544 & 47 & 0.577 & 56 & 0.845 & 30 & 0.504 & 43 & 0.701 & 52 & 0.595 & 47 & 0.6265 & 49 & 0.410 & 70 \\
\hline CI109 & Venezia & 1.000 & 1 & 0.514 & 63 & 0.581 & 54 & 0.690 & 78 & 0.422 & 79 & 0.701 & 52 & 0.553 & 64 & 0.5754 & 72 & 0.635 & 6 \\
\hline CI110 & Verbania & 1.000 & 1 & 0.612 & 22 & 0.689 & 19 & 0.876 & 18 & 0.574 & 23 & 0.816 & 15 & 0.706 & 12 & 0.7107 & 20 & 0.737 & 1 \\
\hline CI112 & Verona & 1.000 & 1 & 0.653 & 15 & 0.679 & 22 & 0.853 & 28 & 0.595 & 17 & 0.826 & 11 & 0.675 & 22 & 0.7126 & 19 & 0.507 & 40 \\
\hline CI113 & Vibo Valentia & 1.000 & 1 & 0.530 & 55 & 0.643 & 33 & 0.828 & 39 & 0.490 & 49 & 0.775 & 26 & 0.640 & 30 & 0.6492 & 38 & 0.208 & 89 \\
\hline CI114 & Vicenza & 0.969 & 14 & 0.547 & 46 & 0.588 & 53 & 0.807 & 47 & 0.512 & 37 & 0.724 & 43 & 0.602 & 43 & 0.6289 & 48 & 0.479 & 49 \\
\hline CI115 & Villacidro & 1.000 & 1 & 0.537 & 50 & 0.688 & 20 & 0.809 & 46 & 0.478 & 58 & 0.769 & 29 & 0.656 & 26 & 0.6538 & 35 & - & - \\
\hline \multirow[t]{5}{*}{ CI116 } & Viterbo & 0.978 & 11 & 0.514 & 63 & 0.557 & 65 & 0.795 & 53 & 0.445 & 70 & 0.650 & 70 & 0.534 & 72 & 0.5812 & 70 & 0.414 & 69 \\
\hline & $\max$ & 1.000 & & 0.816 & & 0.839 & & 0.980 & & 0.732 & & 0.958 & & 0.829 & & 0.8421 & & 0.737 & \\
\hline & $\min$ & 0.516 & & 0.115 & & 0.130 & & 0.070 & & 0.099 & & 0.116 & & 0.135 & & 0.1105 & & 0.162 & \\
\hline & mean & 0.965 & & 0.542 & & 0.587 & & 0.772 & & 0.487 & & 0.689 & & 0.584 & & 0.6091 & & 0.476 & \\
\hline & st.dev & 0.074 & & 0.116 & & 0.123 & & 0.153 & & 0.106 & & 0.142 & & 0.119 & & 0.1228 & & 0.115 & \\
\hline
\end{tabular}


Focusing on the latest 10 positions in the ranking, six cities are located in the isles (Catania, Enna, Nuoro, Palermo, Tempio Pausania), three in the North (Belluno, Imperia, Treviso), and one in the South of Italy (Benevento). In 2011, the small city of Benevento achieved important environmental targets, i.e., an acceptable rate of differentiated waste collection, an average production of solid waste per inhabitant of about $400 \mathrm{~kg}$ and moderate electricity consumption, but it suffered from high levels of pollution in terms of concentration of $\mathrm{PM}_{10}$ and scarce water treatment. Black water treatment still remains a major problem for many cities in the isles, too.

Table 5 presents information relative to the importance degrees utilized to compute the comprehensive ecological efficiency index for sample cities. Data show that Model E has the highest (0.17721) importance degree $\left(W_{p}\right)$, and, as a consequence, the ranking generated by Model E can be adopted as an acceptable substitute to the ranking obtained by calculating XECI. Model E has also the highest diversification degree $\left(d_{p}\right)$ measurement. Model $\mathrm{G}$ has both low importance and diversification degrees measurements and offers an unacceptable discriminatory capability to generate useful rankings.

The Pearson correlations and the Spearman's rank correlations have been calculated to assess the sensitivity of rankings to the particular DEA model (see Tables 6 and 7). Particularly, the Spearman's rank correlation coefficient is a robust measure of similarity between rankings. When the coefficient score is one, the two rankings coincide and, consequently, ranking is not affected by the particular DEA model, while a score of 0 indicates that rankings are absolutely different. The Pearson and Spearman's rank correlation measurements always score less than one, varying from 0.168 to 0.993 and from 0.188 to 0.989 , respectively. As expected, there is a high correlation between DEA cross-efficiencies and the comprehensive index both in terms of efficiency scores and ranks. Both the efficiency measurements and ranks of Model A and the Sole24Ore study are weakly correlated to the efficiency measurements and ranks obtained for the XECI model.

Table 5. Importance degrees of DEA cross-efficiency models.

\begin{tabular}{ccccccc}
\hline Importance Degree & Model B & Model C & Model D & Model E & Model F & Model G \\
\hline $\mathrm{H}_{\mathrm{p}}$ & 0.99477 & 0.99491 & 0.99486 & 0.99450 & 0.99483 & 0.99512 \\
$\mathrm{~d}_{\mathrm{p}}$ & 0.00523 & 0.00509 & 0.00514 & 0.00550 & 0.00517 & 0.00488 \\
$\mathrm{~W}_{\mathrm{p}}$ & 0.16869 & 0.16425 & 0.16586 & 0.17721 & 0.16662 & 0.15737 \\
\hline
\end{tabular}

Table 6. Pearson Correlations between ecological efficiency indices.

\begin{tabular}{cccccccccc}
\hline & Model A & Model B & Model C & Model D & Model E & Model F & Model G & XECI & Sole24Ore \\
\hline Model A & 1.000 & 0.592 & 0.576 & 0.540 & 0.597 & 0.546 & 0.578 & 0.583 & 0.188 \\
Model B & 0.592 & 1.000 & 0.976 & 0.876 & 0.978 & 0.930 & 0.970 & 0.974 & 0.323 \\
Model C & 0.576 & 0.976 & 1.000 & 0.896 & 0.955 & 0.966 & 0.991 & 0.984 & 0.349 \\
Model D & 0.540 & 0.876 & 0.896 & 1.000 & 0.895 & 0.953 & 0.922 & 0.951 & 0.272 \\
Model E & 0.597 & 0.978 & 0.955 & 0.895 & 1.000 & 0.935 & 0.969 & 0.975 \\
Model F & 0.546 & 0.930 & 0.966 & 0.953 & 0.935 & 1.000 & 0.978 & 0.985 & 0.317 \\
Model G & 0.578 & 0.970 & 0.991 & 0.922 & 0.969 & 0.978 & 1.000 & 0.993 & 0.375 \\
XECI & 0.583 & 0.974 & 0.984 & 0.951 & 0.975 & 0.985 & 0.993 & 1.000 & 0.340 \\
Sole24Ore & 0.188 & 0.323 & 0.349 & 0.272 & 0.317 & 0.365 & 0.375 & 0.340 & 1.000 \\
\hline
\end{tabular}

Table 7. Spearman Order Correlations between ranks.

\begin{tabular}{cccccccccc}
\hline & Model A & Model B & Model C & Model D & Model E & Model F & Model G & XECI & Sole24Ore \\
\hline Model A & 1.000 & 0.567 & 0.568 & 0.484 & 0.577 & 0.510 & 0.561 & 0.559 & 0.168 \\
Model B & 0.567 & 1.000 & 0.942 & 0.867 & 0.960 & 0.899 & 0.945 & 0.965 & 0.290 \\
Model C & 0.568 & 0.942 & 1.000 & 0.858 & 0.896 & 0.955 & 0.983 & 0.978 & 0.288 \\
Model D & 0.484 & 0.867 & 0.858 & 1.000 & 0.865 & 0.908 & 0.887 & 0.924 & 0.243 \\
Model E & 0.577 & 0.960 & 0.896 & 0.865 & 1.000 & 0.873 & 0.933 & 0.947 & 0.271 \\
Model F & 0.510 & 0.899 & 0.955 & 0.908 & 0.873 & 1.000 & 0.959 & 0.965 & 0.323 \\
Model G & 0.561 & 0.945 & 0.983 & 0.887 & 0.933 & 0.959 & 1.000 & 0.989 & 0.331 \\
XECI & 0.559 & 0.965 & 0.978 & 0.924 & 0.947 & 0.965 & 0.989 & 1.000 & 0.297 \\
Sole24Ore & 0.168 & 0.290 & 0.288 & 0.243 & 0.271 & 0.323 & 0.331 & 0.297 & 1.000 \\
\hline
\end{tabular}


Finally, Table 8 reports measurements relative to the ecological efficiency comprehensive index XECI of cities grouped by geographical area and population class. Three population classes have been used for grouping cities- "less than 80,000" inhabitants, "between 80,000 and 200,000" inhabitants and "more than 200,000" inhabitants-as in the Sole24Ore ranking technical report. Except for the largest cities located in the isles ("more than 200,000" inhabitants cities), the mean comprehensive ecological efficiency generally increases when the size of the cities increases. Indeed, the mean efficiency is between $56.7 \%$ and $59.4 \%$ in smaller cities ("less than 80,000 " inhabitants), and between $62.4 \%$ and $65.7 \%$ in medium size cities ("between 80,000 and 200,000" inhabitants). In the last group of cities ("more than 200,000" inhabitants), the mean ecological efficiency achieves higher scores in the North, Center and South of Italy, but sharply decreases in the last group of cities located in the isles, because of the lower efficiency values earned by the cities of Catania and Palermo.

Table 8. Measurements of the Shannon's entropy index (XECI) for cities grouped by geographical area and population size.

\begin{tabular}{|c|c|c|c|c|c|c|c|c|c|}
\hline & \multicolumn{3}{|c|}{ Less Than 80,000} & \multicolumn{3}{|c|}{ between 80,000 and 200,000} & \multicolumn{3}{|c|}{ More Than 200,000 } \\
\hline & Cities & $X E C I$ & Population & Cities & $X E C I$ & Population & $n$ Cities & $X E C I$ & Population \\
\hline \multirow{24}{*}{ North } & Imperia & 0.111 & 42,230 & Treviso & 0.288 & 80,822 & Venezia & 0.575 & 261,555 \\
\hline & Belluno & 0.408 & 35,595 & Alessandria & 0.550 & 89,613 & Trieste & 0.645 & 202,346 \\
\hline & Pavia & 0.552 & 68,449 & Ferrara & 0.587 & 132,588 & Padova & 0.694 & 206,284 \\
\hline & Mantova & 0.560 & 46,593 & Como & 0.612 & 81,794 & Verona & 0.713 & 252,720 \\
\hline & Pordenone & 0.566 & 50,499 & Ravenna & 0.618 & 153,096 & Torino & 0.717 & 871,816 \\
\hline & Lodi & 0.579 & 43,285 & Vicenza & 0.629 & 111,755 & Bologna & 0.727 & 370,402 \\
\hline & Cremona & 0.588 & 69,839 & Udine & 0.644 & 98,246 & Genova & 0.745 & 586,162 \\
\hline & Rovigo & 0.590 & 50,040 & Forlì & 0.644 & 116,242 & Milano & 0.815 & $1,235,543$ \\
\hline & Vercelli & 0.598 & 46,179 & Novara & 0.650 & 101,922 & & & \\
\hline & Biella & 0.603 & 43,855 & Bergamo & 0.652 & 115,294 & & & \\
\hline & Lecco & 0.612 & 46,628 & Parma & 0.652 & 175,536 & & & \\
\hline & Asti & 0.614 & 73,874 & Reggio Emilia & 0.662 & 162,093 & & & \\
\hline & Savona & 0.617 & 60,764 & Piacenza & 0.664 & 100,109 & & & \\
\hline & Gorizia & 0.618 & 35,186 & Monza & 0.685 & 119,950 & & & \\
\hline & Varese & 0.627 & 79,654 & La Spezia & 0.692 & 92,604 & & & \\
\hline & Cuneo & 0.632 & 54,857 & Modena & 0.701 & 178,962 & & & \\
\hline & Sondrio & 0.634 & 21,684 & Brescia & 0.717 & 189,331 & & & \\
\hline & Verbania & 0.711 & 30,327 & Bolzano & 0.724 & 102,214 & & & \\
\hline & Aosta & 0.839 & 34,144 & Rimini & 0.732 & 139,360 & & & \\
\hline & & & & Trento & 0.798 & 113,900 & & & \\
\hline & mean & 0.582 & 49,141 & mean & 0.645 & 122,771 & mean & 0.704 & 498,353 \\
\hline & $\max$ & 0.839 & 79,654 & $\max$ & 0.798 & 189,331 & $\max$ & 0.815 & $1,235,543$ \\
\hline & $\min$ & 0.111 & 21,684 & $\min$ & 0.288 & 80,822 & $\min$ & 0.575 & 202,346 \\
\hline & stdev & 0.139 & 15,558 & stdev & 0.101 & 33,195 & stdev & 0.071 & 377,272 \\
\hline \multirow{15}{*}{ Center } & Macerata & 0.472 & 42,013 & Pistoia & 0.470 & 89,154 & Firenze & 0.608 & 356,869 \\
\hline & Frosinone & 0.479 & 46,803 & Pisa & 0.526 & 85,901 & Roma & 0.742 & $2,611,397$ \\
\hline & Rieti & 0.490 & 46,098 & Arezzo & 0.532 & 97,965 & & & \\
\hline & Fermo & 0.557 & 36,899 & Lucca & 0.569 & 86,818 & & & \\
\hline & $\begin{array}{l}\text { Ascoli } \\
\text { Piceno }\end{array}$ & 0.564 & 50,081 & Terni & 0.601 & 109,295 & & & \\
\hline & Viterbo & 0.581 & 62,947 & Pesaro & 0.620 & 94,440 & & & \\
\hline & Massa & 0.615 & 68,847 & Latina & 0.631 & 117,746 & & & \\
\hline & Grosseto & 0.677 & 78,475 & Ancona & 0.660 & 100,696 & & & \\
\hline & Siena & 0.721 & 52,843 & Perugia & 0.664 & 161,910 & & & \\
\hline & & & & Livorno & 0.788 & 156,891 & & & \\
\hline & & & & Prato & 0.802 & 185,153 & & & \\
\hline & mean & 0.573 & 53,889 & mean & 0.624 & 116,906 & mean & 0.675 & $1,484,133$ \\
\hline & $\max$ & 0.721 & 78,475 & $\max$ & 0.802 & 185,153 & $\max$ & 0.742 & $2,611,397$ \\
\hline & $\min$ & 0.472 & 36,899 & $\min$ & 0.470 & 85,901 & $\min$ & 0.608 & 356,869 \\
\hline & stdev & 0.087 & 13,539 & stdev & 0.103 & 34,790 & stdev & 0.094 & $1,594,192$ \\
\hline
\end{tabular}


Table 8. Cont.

\begin{tabular}{|c|c|c|c|c|c|c|c|c|c|}
\hline & \multicolumn{3}{|c|}{ Less Than 80,000} & \multicolumn{3}{|c|}{ between 80,000 and 200,000} & \multicolumn{3}{|c|}{ More Than 200,000 } \\
\hline & Cities & $X E C I$ & Population & Cities & $X E C I$ & Population & $n$ Cities & XECI & Population \\
\hline \multirow{18}{*}{ South } & Benevento & 0.212 & 61,573 & Catanzaro & 0.534 & 89,523 & Taranto & 0.569 & 200,255 \\
\hline & Crotone & 0.532 & 58,913 & Lecce & 0.566 & 89,492 & Napoli & 0.693 & 961,884 \\
\hline & Chieti & 0.561 & 51,513 & Pescara & 0.589 & 117,239 & Bari & 0.723 & 315,946 \\
\hline & Isernia & 0.564 & 21,957 & Reggio Calabria & 0.594 & 180,949 & & & \\
\hline & Cosenza & 0.570 & 69,502 & Foggia & 0.635 & 147,481 & & & \\
\hline & Campobasso & 0.586 & 48,798 & Andria & 0.636 & 99,976 & & & \\
\hline & L'Aquila & 0.610 & 67,196 & Brindisi & 0.661 & 88,698 & & & \\
\hline & Trani & 0.622 & 55,745 & Barletta & 0.681 & 94,122 & & & \\
\hline & Teramo & 0.641 & 54,200 & Salerno & 0.842 & 132,794 & & & \\
\hline & Potenza & 0.646 & 66,771 & & & & & & \\
\hline & $\begin{array}{c}\text { Vibo } \\
\text { Valentia }\end{array}$ & 0.649 & 33,422 & & & & & & \\
\hline & Caserta & 0.698 & 75,578 & & & & & & \\
\hline & Avellino & 0.701 & 54,309 & & & & & & \\
\hline & Matera & 0.720 & 59,750 & & & & & & \\
\hline & mean & 0.594 & 55,659 & mean & 0.638 & 115,586 & mean & 0.662 & 492,695 \\
\hline & $\max$ & 0.720 & 75,578 & $\max$ & 0.842 & 180,949 & $\max$ & 0.723 & 961,884 \\
\hline & $\min$ & 0.212 & 21,957 & $\min$ & 0.534 & 88,698 & $\min$ & 0.569 & 200,255 \\
\hline & stdev & 0.124 & 14,158 & stdev & 0.090 & 32,357 & stdev & 0.082 & 410,426 \\
\hline \multirow{19}{*}{ Isles } & Enna & 0.369 & 27,907 & Siracusa & 0.548 & 118,888 & Catania & 0.221 & 294,461 \\
\hline & Agrigento & 0.403 & 58,216 & Cagliari & 0.700 & 149,937 & Palermo & 0.335 & 658,078 \\
\hline & $\begin{array}{c}\text { Tempio } \\
\text { Pausania }\end{array}$ & 0.407 & 13,951 & Sassari & 0.724 & 123,677 & Messina & 0.624 & 243,380 \\
\hline & Nuoro & 0.431 & 36,682 & & & & & & \\
\hline & Caltanissetta & 0.436 & 61,697 & & & & & & \\
\hline & Iglesias & 0.464 & 27,688 & & & & & & \\
\hline & Trapani & 0.561 & 69,177 & & & & & & \\
\hline & Ragusa & 0.594 & 69,832 & & & & & & \\
\hline & Olbia & 0.621 & 53,079 & & & & & & \\
\hline & Lanusei & 0.627 & 5,488 & & & & & & \\
\hline & Villacidro & 0.654 & 14,291 & & & & & & \\
\hline & Sanluri & 0.666 & 8,460 & & & & & & \\
\hline & Carbonia & 0.729 & 28,885 & & & & & & \\
\hline & Oristano & 0.762 & 31,166 & & & & & & \\
\hline & Tortolì & 0.782 & 10,716 & & & & & & \\
\hline & mean & 0.567 & 34,482 & mean & 0.657 & 130,834 & mean & 0.393 & 398,639 \\
\hline & $\max$ & 0.782 & 69,832 & $\max$ & 0.724 & 149,937 & $\max$ & 0.624 & 658,078 \\
\hline & $\min$ & 0.369 & 5,488 & $\min$ & 0.548 & 118,888 & $\min$ & 0.221 & 243,380 \\
\hline & stdev & 0.140 & 22,601 & stdev & 0.095 & 16,716 & stdev & 0.208 & 226,127 \\
\hline
\end{tabular}

\section{Conclusions}

The prosperity and the development of nations are largely influenced by the growth of their cities. While cities are an important source of growth and economic competitiveness, at the same time, they are huge consumers of resources and energy, and producers of waste and greenhouse gas emissions.

In the last two decades, a number of factors have induced the policy makers and city planners to rethink the development and management model of cities, such as the advent of climate change, the shortage of fossil fuels and natural resources, the high costs related to the solid waste disposal, the increasing traffic congestion and the unpropitious impact of pollution on human health. In this context, improving the city ecological efficiency has become an important task of local administrators to make their cities more attractive, livable and environmentally sustainable. Measuring the results of the policies and actions implemented to enhance the sustainability level of cities is thus necessary to assess their effectiveness and efficiency. Rankings and benchmarking studies can be indeed an important tool for the city administration to make the city more ecologically efficient and environmentally sustainable, attractive and, finally, more competitive. Placing at a high rank of the ranking helps improving the image of the city and the reputation of the local government, and, as a consequence, can have 
an important role to support the marketing strategy of the city and attract funds from the central government and the private sector.

However, ranking metrics and methodologies often suffer from methodological drawbacks and remain opaque with a high degree of subjectivity related to the choice of indicators and, particularly, weighting schemes. Indeed, using ranking methods based on subjective weighting schemes may be inappropriate as weights reflect the preferences of a specific audience. Rankings can be very sensitive to weights and even very small changes in the weighting scheme can seriously impact the ranking order, and it is common that they are many times open to manipulation.

This paper has proposed a robust and transparent method that implements Data Envelopment Analysis and the Shannon's entropy index to construct an aggregated measurement of city sustainability in the form of an ecological efficiency comprehensive index. The proposed methodological framework has the advantage to combine together a set of indicators that reflect the diversity of many ecological efficiency areas and different evaluation perspectives. In the method, the weighting scheme used to aggregate partial indicators is generated endogenously from the data. In addition, the flexibility of the method allows the inclusion of a variable set of indicators in order to customize the measurement of the ecological efficiency index to the specific needs of the context, and, more important, to the availability of data.

As an empirical application, the index has been used to measure the ecological efficiency for a sample of 116 Italian provincial capital cities. The outcome of city rankings highlights a remarkable variability in the sample of cities. The score of the comprehensive index that measures the ecological efficiency is between $11.05 \%$ and $84.21 \%$. In particular, on the one hand, there are a large number of cities where, over years, the local governments planned and implemented several projects and specific policies to improve urban environmental sustainability. These cities achieved a higher ecological efficiency score and perform better on the ranking. This is the case of Salerno (84.2\%) in the South of Italy, Aosta (83.9\%), Genova (74.5\%), Milano (81.5\%) and Trento $(79.8 \%)$ in the North, Livorno $(78.8 \%)$, Prato $(80.2 \%)$ and Roma $(74.2 \%)$ in the Center, and Oristano $(76.2 \%)$ and Tortoli $(78.2 \%)$ in the Isles. On the other hand, there are urban contexts where there is still a lack of attention to environmental issues and sustainability, above all as a consequence of the territorial, economic and infrastructural divide. As a general behavior, the ecological efficiency measurement increases when the size of the city increases. However, the largest cities which are located in the Isles are poorly performing. Differences between cities can be even more marked than differences between regions.

Results show that the proposed DEA framework based on the implementation of various cross-efficiency DEA models and the Shannon's entropy index produces an evaluation of the city ecological efficiency that differs from that provided by the economic newspaper Sole24Ore which is typically assumed as a reference in Italy for city comparisons. Main reasons of this difference are the utilization of a different set of environment-related statistics and of subjective weights introduced in the calculation of the index provided by the Sole24Ore study. On the contrary, the adoption of DEA as a general method limits the subjectivity needed for the analysis to the choice of the DEA models (i.e., the input and output variables). In this way, a ranking of cities with respect to their ecological efficiency can be generated by means of a more objective methodology. Therefore, using DEA as a method for generating an ecological efficiency measurement allows having some degree of standardization and comparability. Moreover, the DEA-Shannon's entropy based index provides useful and easy-to-communicate information to rank and compare cities with respect to their environmental sustainability with an acceptable discrimination capability.

The city governments can use the ranking measurements generated by the index to conduct useful benchmarking analyses, and identify the city strengths and weaknesses compared with peer cities. Furthermore, performing a more in-depth analysis within the group of city peers looking at the measurements of individual indicators used to construct the comprehensive measurement can suggest where the city has to improve to increase its progress to ecological efficiency by monitoring the performance of the city over time. Benchmarking and city rankings are fundamental pre-requisites 
for the political decision makers and administrators to give account of their actions, forcing them to make their decisions transparent and comprehensible to stakeholders, becoming an important tool to promote democracy and participation by attracting attention and stimulating discussion on sustainable strategies, and supporting shared learning. Thus, the proposed index becomes an indispensable tool for the development of plans and policy measures to promote the ecological efficiency in the cities.

Of course, measuring the city ecological efficiency is not an exact science. The development of the proposed index is a work in progress, and a longitudinal analysis is necessary to further test its strengths or weaknesses. It has been computed for one single year, providing a static representation of the ecological efficiency scores of the cities in the sample, but its calculation can be easily extended to several years if reliable and objective data are available to perform benchmarking analyses over time. There are some critical non-discretionary variables that are beyond the control of the city government which can influence the ecological efficiency measurement and, henceforth, need consideration. A more in depth research effort should take into account factors such as climate, territory topology, infrastructure development, and so on. Unlike country or regional data which are generally available thanks to the work carried on by the National Statistical Offices, collecting data at the city level is still at the beginning. Therefore, the lack of reliable, high quality and cost effective data is a major challenge, no matter how the ranking methodology can be rigorous and supported by a sound theory. Moreover, even though the relevant advantage of the method is its objectivity, the extreme flexibility of DEA allows the introduction in the model of thresholds, weight restrictions, and economic payoffs that take into account specific policy goals.

It should be recognized that city comparisons and the examination of the effect of policies and measures to support city sustainability are complex and require a more in depth analysis than that allowed by a single ranking index. Thus, caution is necessary when the proposed index is used to assess the efficacy of environmental policies. According to literature relative to the measurement of urban sustainability and ecological efficiency no single indicator set or index are appropriate for every application and implementable in practice. Henceforth, the proposed comprehensive index should not be considered as a substitute, but rather utilized together with other methods.

Acknowledgments: The author is grateful to the four anonymous referees whose comments and suggestions improved the quality of this work.

Conflicts of Interest: The author declares no conflict of interest.

\section{Appendix}

Supposing that the set of input variables is partitioned into the subset of discretionary input variables $\left(I_{D}\right)$ and the subset of non-discretionary (uncontrollable) input variables $\left(I_{N D}\right)$ so that $I_{D} \cup I_{N D}=I=\{1, \ldots, m\}$ and $I_{D} \cap I_{N D}=\varnothing$, models (3), (4), (5) and (6) are modified as follows:

$$
\begin{gathered}
\operatorname{Max} \sum_{r=1}^{s} u_{r k} y_{r k}-\sum_{i \in I_{N D}} v_{i k} x_{i k}+u_{* k} \\
\text { s.t. } \sum_{i \in I_{D}} v_{i k} x_{i k}=1 \\
\sum_{r=1}^{s} u_{r k} y_{r j}-\left(\sum_{i \in I_{D}} v_{i k} x_{i j}+\sum_{i \in I_{N D}} v_{i k} x_{i j}\right)+u_{* k} \leqslant 0 \quad j=1, \ldots, n \\
u_{r k} \geqslant 0, v_{i k} \geqslant 0, u_{* k} \text { free, } i \in I_{D}, i \in I_{N D} \text { and } r=1, \ldots, s \\
\sum_{k k}=\frac{\sum_{r=1}^{s} u_{r k}^{*} y_{r k}-\sum_{i \in I_{N D}} v_{i k}^{*} x_{i k} x_{i k}+u_{* k}}{\sum_{i \in I_{D}}} \quad i \in I_{D}, i \in I_{N D}
\end{gathered}
$$




$$
\begin{gathered}
E_{k j}=\frac{\sum_{r=1}^{s} u_{r k}^{*} y_{r j}-\sum_{i \in I_{N D}} v_{i k}^{*} x_{i j}+u_{* k}}{\sum_{i \in I_{D}} v_{i k}^{*} x_{i j}} \quad i \in I_{D}, i \in I_{N D}, j \neq k \text { and } j=1, \ldots, n \\
\min \sum_{r=1}^{s} u_{r k}\left(\sum_{j=1, j \neq k}^{n} y_{r j}\right)-\sum_{i \in I_{N D}} v_{i k}\left(\sum_{j=1, j \neq k}^{n} x_{i j}\right)+u_{* k} \\
\text { s.t. } \sum_{i \in I_{D}} v_{i k}\left(\sum_{j=1, j \neq k}^{n} x_{i j}\right)=1 \\
\sum_{r=1}^{s} u_{r k} y_{r k}-\sum_{i \in I_{N D}} v_{i k} x_{i k}-E_{k k}^{*} \sum_{i \in I_{D}} v_{i k} x_{i k}+u_{* k}=0 \\
\sum_{r=1}^{s} u_{r k} y_{r j}-\sum_{i \in I_{D}} v_{i k} x_{i j}-\sum_{i \in I_{N D}} v_{i k} x_{i j}+u_{* k} \leqslant 0 \\
u_{r k} \geqslant 0, v_{i j} \geqslant 0, u_{* k} \text { free, } \quad i \in I_{D}, i \in I_{N D}, \quad j=1, \ldots, n \text { for } j \neq k, \quad r=1, \ldots, s .
\end{gathered}
$$

\section{References}

1. Parilla, J.; Trujillo, J.L.; Berube, A.; Ran, T. Global Metro Monitor: An Uncertain Recovery. Available online: www.brookings.edu/metro (accessed on 28 August 2015).

2. Seto, K.C.; Dhakal, S.; Bigio, A.; Blanco, H.; Delgado, G.C.; Dewar, D.; Huang, L.; Inaba, A.; Kansal, A.; Lwasa, S.; et al. Human Settlements, Infrastructure and Spatial Planning. In Climate Change 2014: Mitigation of Climate Change. Contribution of Working Group III to the Fifth Assessment Report of the Intergovernmental Panel on Climate Change; Edenhofer, O., Pichs-Madruga, R., Sokona, Y., Farahani, E., Kadner, S., Seyboth, K., Adler, A., Baum, I., Brunner, S., Eickemeier, P., et al, Eds.; Cambridge University Press: Cambridge, UK; New York, NY, USA, 2014.

3. Dobbs, R.; Smit, S.; Remes, J.; Manyika, J.; Roxburgh, C.; Restrepo, A. Urban world: Mapping the Economic Power of Cities. Available online: http://www.mckinsey.com/Insights/MGI/Research/ Urbanization/Urban world (accessed on 22 August 2015).

4. UN-HABITAT. State of the World's Cities 2010/2011: Bridging the Urban Divide. Available online: http:/ / www.unhabitat.org/pmss/listItemDetails.aspx?publicationID=2917 (accessed on 29 July 2015).

5. UN-ESCAP. Are We Building Competitive and Livable Cities? Guidelines for Developing Eco-Efficient and Socially Inclusive Infrastructure. Available online: http://www.unescap.org/sites/default/files/ Guides\%20for\%20developing\%20eco\%20efficient\%20infra_full.pdf (accessed on 13 August 2015).

6. OECD. OECD Territorial Reviews: Competitive Cities in the Global Economy; OECD Publishing: Paris, France, 2006.

7. Bieri, D.S. Are Green Cities Nice Places to Live? On the Link between Sustainability and Quality of Life. Mich. J. Sustain. 2013, 1, 44-73. [CrossRef]

8. UN-ESCAP. Eco-efficiency Indicators: Measuring Resource-Use Efficiency and the Impact of Economic Activities on the Environment, ST/ESCAP/2561 Working Paper; United Nations Publication: New York, NY, USA, 2009.

9. Mickwitz, P.; Melanen, M.; Rosenstroem, U.; Seppälä, J. Regional eco-efficiency indicators-A participatory approach. J. Clean. Prod. 2006, 14, 1603-1611. [CrossRef]

10. Saltelli, A.; Munda, G.; Nardo, M. From complexity to multi-dimensionality: The role of composite indicators for advocacy of EU reform. Tijds Econ. Manag. 2006, 3, 221-235.

11. OECD. Green Growth Indicators; OECD Publishing: Paris, France, 2014.

12. Simpson, R.; Zimmermann, M.; Salz, S.; Kelleher, S. GIZ and ICLEI, 2012, Discussion Paper: Green Urban. Economy-Conceptual Basis and Courses for Action. 2012. Available online: http://www.iclei.org/ fileadmin/PUBLICATIONS/Global_Reports/ICLEI-GIZ_Green_Urban_Economy_Study_2013.pdf (accessed on 21 August 2015).

13. United Nations. Indicators of Sustainable Development: Guidelines and Methodologies; United Nations: New York, NY, USA, 2007; Available online: http://www.un.org/esa/sustdev/natlinfo/indicators/guidelines.pdf (accessed on 28 August 2015). 
14. World Bank. World Development Report 2005: A Better Investment Climate for Everyone; World Bank: Washington, DC, USA, 2004; Available online: http://siteresources.worldbank.org/INTWDR2005/ Resources/complete_report.pdf (accessed on 11 August 2015).

15. World Bank. World Development Indicators 2013; World Bank: Washington, DC, USA, 2013; Available online: http:/ / databank.worldbank.org/data/download/WDI-2013-ebook.pdf (accessed on 28 August 2015).

16. UN-HABITAT. Sustainable Urban Energy Planning: A Handbook for Cities and Towns in Developing Countries. Available online: http://www.uncsd2012.org/content/documents/ Sustainable\%20Urban\%20Energy\%20Planning.pdf (accessed on 30 August 2015).

17. Olsthoorn, X.; Tyteca, D.; Wagner, M.; Wehrmeyer, W. Environmental indicators for business: A review of the literature and standardisation methods. J. Clean. Prod. 2001, 9, 453-463. [CrossRef]

18. United Nations. Are We Building Competitive and Livable Cities? Guidelines for Developing Eco-Efficient and Socially Inclusive Infrastructure; Clung Wicha Press: Bangkok, Thailand, 2011; Available online: http://www.greengrowthknowledge.org/sites/default/files/downloads/resource/uneclacunescap-unhabitat-Guidelines.pdf (accessed on 29 August 2015).

19. GRI. The Sustainability Reporting Guidelines, Global Reporting Initiative. Available online: http:/ / www.epeat.net/documents/EPEATreferences/GRIguidelines.pdf (accessed on 7 August 2015).

20. Esty, D.C.; Simmons, P.J. Green to Gold Business Playbook: How to Implement. Sustainability Practices for Bottom-Line Results in Every Business Function; John Wiley \& Sons Inc.: New Jersey, NJ, USA, 2011.

21. Emerson, J.; Esty, D.C.; Levy, M.A.; Kim, C.H.; Mara, V.; de Sherbinin, A.; Srebotnjak, T. 2010 Environmental Performance Index; Yale Center for Environmental Law and Policy: New Haven, CT, USA, 2010.

22. Eurostat. Database: Statistics Relative to 2011. Available online: http://ec.europa.eu/eurostat/data/ database (accessed on 10 June 2015).

23. EIU. Global Livability Ranking. Available online: http://www.eiu.com/public/topical_report.aspx? campaignid=Liveability2015 (accessed on 28 August 2015).

24. Dual Citizen LLC. The Global Green Economy Index GGEI 2014: Measuring National Performance in the Green Economy. Available online: http:/ /dualcitizeninc.com/GGEI-Report2014.pdf (accessed on 20 August 2015).

25. Mercer, H.R. Sustainability in the Corporate World Research Report. 2014. Available online: http://www.mercer.com/content/dam/mercer/attachments/global/investments/responsible-investment/ Mercer-Sustainability-Research-Report-July-2014.pdf (accessed on 12 August 2015).

26. Arcadis. Sustainable Cities Index 2015. Available online: https://s3.amazonaws.com/arcadis-whitepaper/ arcadis-sustainable-cities-index-report.pdf (accessed on 1 September 2015).

27. Arcadis. Sustainability of global cities held back by social factors, says new index. Available online: http:// www.arcadis-us.com/press/Sustainability_of_global_cities_held_back_by_social_factors_says_new_index. aspx (accessed on 1 September 2015).

28. Burck, J.; Marten, F.; Bals, C. The Climate Change Performance Index Results 2015. Available online: http//www.germanwatch.org/en/ccpi (accessed on 1 September 2015).

29. Hsu, A.; Emerson, J.; Levy, M.; de Sherbinin, A.; Johnson, L.; Malik, O.; Schwartz, J.; Jaiteh, M. The 2014 Environmental Performance Index; Yale Center for Environmental Law \& Policy: New Haven, CT, USA, 2014; Available online: www.epi.yale.edu (accessed on 13 August 2015).

30. Parad, M.; Henningsson, S.; Currás, T.A.; Youngman, R. The Global Cleantech Innovation Index 2014. Available online: http://www.cleantech.com/wp-content/uploads/2014/08/Global_Cleantech_Innov_Index_2014. pdf (accessed on 28 August 2015).

31. UNEP. Towards a Green Economy: Pathways to Sustainable Development and Poverty Eradication. Available online: http:/ / www.unep.org/greeneconomy (accessed on 12 August 2015).

32. PwC. Two Degrees of Separation: Ambition and Reality-Low Carbon Economy Index. Available online: http:/ / www.pwc.co.uk/assets/pdf/low-carbon-economy-index-2014.pdf (accessed on 3 September 2015).

33. EY. RECAI-Renewable Energy Country Attractiveness Index 2015. Available online: http://www.ey.com/Publication/vwLUAssets/Renewable_Energy_Country_Attractiveness_Index_43/ \$FILE/RECAI\%2043_March\%202015.pdf (accessed on 29 August 2015).

34. SISTAN. Il Benessere Equo e Sostenibile Delle Città. Available online: http://www.istat.it/it/files/2015/04/ UrBes_2015.pdf (accessed on 29 August 2015). (In Italian) 
35. Sole24Ore. Qualità Della Vita 2014. 2015. Available online: http://www.ilsole24ore.com/pdf2010/Editrice/ ILSOLE24ORE/ILSOLE24ORE/Online/_Oggetti_Correlati/Documenti/Notizie/2014/11/qualita-vitapagella-2014.pdf (accessed on 29 July 2015).

36. ItaliaOggi. Ricerca Sulla Qualità Della Vita 2014. 2015. Available online: http://www.italiaoggi.it/news / dettaglio_news.asp?id=201412262005032967\&chkAgenzie=ITALIAOGGI (accessed on 25 July 2015). (In Italian)

37. LegaAmbiente. Ecosistema Urbano: XXI Rapporto Sulla Qualità Ambientale dei Comuni Capoluogo di Provincia. 2014. Available online: http://www.legambiente.it/sites/default/files/docs/ ecosistema_urbano_2014.pdf (accessed on 29 July 2015). (In Italian).

38. Mori, K.; Christodoulou, A. Review of sustainability indices and indicators: Towards a new City Sustainability Index (CSI). Environ. Impact Assess. Rev. 2012, 32, 94-106. [CrossRef]

39. Maclaren, V.W.V. Urban sustainability reporting. J. Am. Plan. Assoc. 1996, 62, 184-202. [CrossRef]

40. Ravetz, J. Integrated assessment for sustainability appraisal in cities and regions. Environ. Impact Assess. Rev. 2000, 20, 31-64. [CrossRef]

41. Lo Storto, C. Benchmarking operational efficiency in the integrated water service provision: Does contract type matter? Benchmarking Int. J. 2014, 21, 917-943. [CrossRef]

42. Nan, Z.; Williams, C.J. An. International Review of Eco-City Theory, Indicators, and Case Studies; Lawrence Berkeley National Laboratory: Berkeley, CA, USA, 2013.

43. Wackernagel, M.; Rees, W.E. Our Ecological Footprint: Reducing Human Impact on the Earth; Gabriola Press New Society Publishing: Gabriola, BC, Canada, 1996.

44. Fang, K.; Heijungs, R.; Duan, Z.; de Snoo, G.R. The Environmental Sustainability of Nations: Benchmarking the Carbon, Water and Land Footprints against Allocated Planetary Boundaries. Sustainability 2015, 7, 11285-11305. [CrossRef]

45. Odum, H.T. Environmental Accounting, Emergy and Decision Making; John Wiley: New York, NY, USA, 1996.

46. Dinarès, M. Urban Metabolism: A Review of Recent Literature on the Subject. Doc. d'Anàlisi Geogr. 2014, 60, 551-571.

47. Wang, Q.; Su, B.; Sun, J.; Zhou, P.; Zhou, D. Measurement and decomposition of energy-saving and emissions reduction performance in Chinese cities. Appl. Energ. 2015, 151, 85-92. [CrossRef]

48. Cuesta, R.A.; Knox Lovell, C.A.; Zofio, J.L. Environmental efficiency measurement with translog distance functions: A parametric approach. Ecol. Econ. 2009, 68, 2232-2242. [CrossRef]

49. Zhou, P.; Ang, B.W.; Poh, K.L. Slack-based efficiency measures for modeling environmental performance. Ecol. Econ. 2006, 60, 111-118. [CrossRef]

50. Zhang, B.; Bi, J.; Fan, Z.Y.; Yan, Z.W.; Ge, J.J. Eco-efficiency analysis of industrial system in China: A data envelopment analysis approach. Ecol. Econ. 2008, 68, 306-316. [CrossRef]

51. Yue, W.; Cai, Y.; Rong, Q.; Cao, L.; Wang, X. A hybrid MCDA-LCA approach for assessing carbon foot-prints and environmental impacts of China's paper producing industry and printing services. Environ. Syst. Res. 2014, 3, 1-9. [CrossRef]

52. Li, D.Z.; Hui, E.C.M.; Leung, B.Y.P.; Li, Q.M.; Xu, X. A methodology for eco-efficiency evaluation of residential development at city level. Build. Environ. 2010, 45, 566-573. [CrossRef]

53. Geng, Y.; Zhang, L.; Chen, X.; Xue, B.; Fujita, T.; Dong, H. Urban ecological footprint analysis: A comparative study between Shenyang in China and Kawasaki in Japan. J. Clean. Prod. 2014, 75, 130-142. [CrossRef]

54. Ulgiati, S.; Brown, M.T. Emergy and ecosystem complexity. Commun. Nonlinear Sci. 2009, 14, $310-321$. [CrossRef]

55. Pizzigallo, A.C.I.; Niccolucci, V.; Caldana, A.; Guglielmi, M.; Marchettini, N. Ecodynamics of territorial systems: An emergy evaluation through time. WIT Trans. Ecol. Environ. 2007, 106, 145-153.

56. Hau, J.L.; Bakshi, B.R. Promise and problems of emergy analysis. Ecol. Model. 2004, 178, 215-225. [CrossRef]

57. Wolman, A. The metabolism of cities. Sci. Am. 1965, 213, 178-193. [CrossRef]

58. Zhang, Y.; Zhao, Y.W.; Yang, Z.F.; Chen, B.; Chen, G.Q. Measurement and evaluation of the metabolic capacity of an urban ecosystem. Commun. Nonlinear Sci. 2009, 14, 1758-1765. [CrossRef]

59. Golubiewski, N. Is there a metabolism of an urban ecosystem? An ecological critique. Ambio 2012, 41, 751-764. [CrossRef] [PubMed]

60. Yin, K.Y.; Wang, R.; An, Q.; Yao, L.; Liang, J. Using eco-efficiency as an indicator for sustainable urban development: A case study of Chinese provincial capital cities. Ecol. Indic. 2014, 36, 665-671. [CrossRef] 
61. Wang, Y.; Sun, M.; Lou, F. Promoting regional sustainability by eco-province construction in China: A critical assessment. Ecol. Indic. 2015, 51, 127-138. [CrossRef]

62. Böhringer, C.; Jochem, P. Measuring the Immeasurable: A Survey of Sustainability Indices. Available online: ftp:/ / ftp.zew.de/pub/zew-docs/dp/dp06073.pdf (accessed on 5 September 2015).

63. Esty, D.C.; Levy, M.A.; Srebotnjak, T.; de Sherbinin, A. Environmental Sustainability Index: Benchmarking National Environmental Stewardship; Yale Center for Environmental Law \& Policy: New Haven, CT, USA, 2005.

64. Esty, D.C.; Levy, M.A.; Srebotnjak, T.; de Sherbinin, A.; Kim, C.H.; Anderson, B. Pilot 2006 Environmental Performance Index; Yale Center for Environmental Law \& Policy: New Haven, CT, USA, 2006.

65. OECD. Handbook on Constructing Composite Indicators: Methodology and User Guide; OECD Publishing: Paris, France, 2008; Available online: http:/ /www.oecd.org/std/42495745.pdf (accessed on 23 August 2015).

66. Tanguay, G.A.; Rajaonson, J.; Lefebvre, J.F.; Lanoie, P. Measuring the sustainability of cities: An analysis of the use of local indicators. Ecol. Indic. 2009, 10, 407-418. [CrossRef]

67. Michael, F.L.; Zainon Noor, Z.; Zardari, N.H.; Figueroa Meza, M.J. Analytical Hierarchy Process Application in Urban Sustainability Indicators Prioritization. Resour. Environ. 2013, 3, 1-5.

68. Aldegheishem, A. Evaluating the Urban Sustainable Development on the Basis of AHP: A Case Study for Riyadh City. J. Sustain. Dev. 2014, 7, 113-120. [CrossRef]

69. Hesari, A.R.E.; Mousavi, S.C.; Behmand, D.; Samadi, R. Prioritizing the Sustainable Development Components and its Role in the improvement of Urban Effete Fabrics with group Analytical Hierarchy Process (AHP): A Central Part of Isfahan City Case Study. J. Civil. Eng. Urban. 2012, 2, 86-91.

70. Sengupta, D.; Mukherjee, R.; Sikdar, S.K. Environmental Sustainability of Countries Using the UN MDG Indicators by Multivariate Statistical Methods. Environ. Prog. Sustain. Energy 2015, 34, 198-206. [CrossRef]

71. Zofio, J.L.; Prieto, A.M. Environmental efficiency and regulatory standards: The case of $\mathrm{CO}_{2}$ emissions from OECD industries. Resour. Energy Econ. 2001, 23, 63-83. [CrossRef]

72. Zhou, P.; Ang, B.W.; Poh, K.L. A survey of data envelopment analysis in energy and environment studies. Eur. J. Oper. Res. 2008, 189, 1-18. [CrossRef]

73. Zhou, P.; Ang, B.W.; Poh, K.L. Measuring environmental performance under different environmental DEA technologies. Energ. Econ. 2008, 30, 1-14. [CrossRef]

74. Zhou, P.; Poh, K.L.; Ang, B.W. A non-radial DEA approach to measuring environmental performance. Eur. J. Oper. Res. 2007, 178, 1-9. [CrossRef]

75. Cherchye, L.; Kuosmanen, T. Benchmarking Sustainable Development: A Synthetic Meta-Index Approach. In Understanding Human Well-Being; McGillivray, M., Clarke, M., Eds.; United Nations University Press: Tokyo, Japan, 2006; pp. 139-168.

76. Lu, W.M.; Lo, S.F. A benchmark-learning roadmap for regional sustainable development in China. J. Oper. Res. Soc. 2007, 58, 841-849. [CrossRef]

77. Wang, Y.C.; Wang, Y.; Zhu, X.D.; Wu, X.Q.; Wang, K.; Ren, K.X.; Lu, G.F. Eco-efficiency change and its driving factors in Tongling City of Anhui Province. Chin. J. Appl. Ecol. 2011, 22, 460-466.

78. Huang, J.; Yang, X.; Cheng, G.; Wang, S. A comprehensive eco-efficiency model and dynamics of regional eco-efficiency in China. J. Clean. Prod. 2014, 67, 228-238. [CrossRef]

79. Üstün, A.K. Evaluating environmental efficiency of Turkish cities by data Envelopment Analysis. Glob. Nest J. 2015, 17, 281-290.

80. Yu, Y.; Wen, Z. Evaluating China's urban environmental sustainability with data Envelopment Analysis. Ecol. Econ. 2010, 69, 1748-1755. [CrossRef]

81. Charnes, A.; Cooper, W.W.; Rhodes, E. Measuring the efficiency of decision making units. Eur. J. Oper. Res. 1978, 2, 429-444. [CrossRef]

82. Cooper, W.W.; Seiford, L.M.; Tone, K. Data Envelopment Analysis; A Comprehensive Text with Models, Applications, References and DEA-Solver Software, 2nd ed.; Springer-Verlag: Berlin, Germany, 2006.

83. Noorizadeh, A.; Mahdiloo, M.; Saen, R.F. Using DEA Cross-efficiency Evaluation for Suppliers Ranking in the Presence of Non-discretionary Inputs. Int. J. Ship. Trans. Log. 2013, 5, 95-111. [CrossRef]

84. Wong, W.P.; Wong, K.Y. A Review on Benchmarking of Supply Chain Performance Measures. Benchmarking Int. J. 2008, 15, 25-51. [CrossRef]

85. Banker, R.D.; Charnes, A.; Cooper, W.W. Some models for estimating technical and scale inefficiencies in data envelopment analysis. Manag. Sci. 1984, 30, 1078-1092. [CrossRef] 
86. Sexton, T.R.; Silkman, R.H.; Hogan, A.J. Data envelopment analysis: Critique and extensions. In Measuring Efficiency: An Assessment of data Envelopment Analysis; Silkman, R.H., Ed.; Jossey-Bass: New York, NY, USA, 1986; pp. 73-105.

87. Sinuany-Stern, Z.; Friedman, L. Data envelopment analysis and the discriminant analysis of ratios for ranking units. Eur. J. Oper. Res. 1998, 111, 470-478. [CrossRef]

88. Anderson, T.R.; Hollingsworth, K.B.; Unman, L.B. The fixed weight nature of a cross-evaluation model. J. Prod. Anal. 2002, 18, 249-255. [CrossRef]

89. Doyle, J.R.; Green, R.H. Efficiency and cross-efficiency in DEA: Derivations, meanings and uses. J. Oper. Res. Soc. 1994, 45, 567-578. [CrossRef]

90. Green, R.H.; Doyle, J.R.; Cook, W.D. Preference voting and project ranking using data envelopment analysis and cross-evaluation. Eur. J. Oper. Res. 1996, 90, 461-472. [CrossRef]

91. Soares de Mello, J.C.; Angulo Meza, L.; da Silveira, J.Q.; Gomes, E.G. About negative efficiencies in Cross Evaluation BCC input oriented models. Eur. J. Oper. Res. 2013, 229, 732-737. [CrossRef]

92. Bian, Y.; Yang, F. Resource and environment efficiency analysis of provinces in China: A DEA approach based on Shannon's entropy. Energ. Policy 2010, 38, 1909-1917. [CrossRef]

93. Zeleny, M. Multiple Criteria Decision Making; McGraw-Hill: New York, NY, USA, 1982.

94. Soleimani-damaneh, M.; Zarepisheh, M. Shannon's entropy for combining the efficiency results of different DEA models: Method and application. Expert Syst. Appl. 2009, 36, 5146-5150. [CrossRef]

95. Jayaraman, A.R.; Srinivasan, M.R. Performance Evaluation of Banks in India-A Shannon-DEA Approach. Eurasian J. Bus. Econ. 2014, 7, 51-68.

96. Xie, Q.; Dai, Q.; Li, Y.; Jiang, A. Increasing the Discriminatory Power of DEA Using Shannon's Entropy. Entropy 2014, 16, 1571-1585. [CrossRef]

97. Bougnol, M.; Dulá, J.H. Validating DEA as a ranking tool: An application of DEA to assess performance in higher education. Ann. Oper. Res. 2006, 145, 339-365. [CrossRef]

98. Thanassoulis, E. Introduction to Theory and Application of Data Envelopment Analysis; Kluwer Academic Publishers: Norwell, MA, USA, 2001.

99. Camanho, A.S.; Portela, M.C.; Vaz, C.B. Efficiency Analysis Accounting for Internal and External Non-discretionary Factors. Comput. Oper. Res. 2009, 36, 1591-1601. [CrossRef]

100. Banker, R.; Morey, R.C. Efficiency Analysis for Exogenously Fixed Inputs and Outputs. Oper. Res. 1986, 34, 513-521. [CrossRef]

101. Yang, H.; Pollit, M.G. Incorporating Both Undesirable Outputs and Uncontrollable Variables into DEA: The Performance of Chinese Coal-fired Power Plants. Eur. J. Oper. Res. 2009, 197, 1095-1105. [CrossRef]

102. Korhonen, P.J.; Luptacik, M. Eco-efficiency Analysis of Power Plants: An Extension of Data Envelopment Analysis. Eur. J. Oper. Res. 2004, 154, 437-446. [CrossRef]

103. Tyteca, D. Linear Programming Models for the Measurement of Environmental Performance of Firms-Concepts and Empirical Results. J. Prod. Anal. 1997, 8, 183-197. [CrossRef]

104. Scheel, H. Undesirable outputs in efficiency valuations. Eur. J. Oper. Res. 2001, 132, 400-410. [CrossRef]

105. Hailu, A.; Veeman, T.S. Non-Parametric Productivity Analysis with Undesirable Outputs: An Application to the Canadian Pulp and Paper Industry. Am. J. Agric. Econ. 2001, 83, 605-616. [CrossRef]

106. Lehni, M. Eco-Efficiency: Creating More Value with Less Impact; World Council for Sustainable Business Development: Switzerland, Geneva, 2000; Available online: http://oldwww.wbcsd.org/web/publications/ eco_efficiency_creating_more_value.pdf (accessed on 10 June 2015).

(C) 2016 by the author; licensee MDPI, Basel, Switzerland. This article is an open access article distributed under the terms and conditions of the Creative Commons by Attribution (CC-BY) license (http://creativecommons.org/licenses/by/4.0/). 